\title{
Modern Perspectives of Curcumin and its Derivatives as Promising Bioactive and Pharmaceutical Agents
}

\author{
Mohd Yusuf ${ }^{1, *(1)}$, Sadiya ${ }^{1,2}$ (i) , Bilal Ahmed ${ }^{1}$ (D) , Mohd Gulfishan ${ }^{3(D)}$ \\ 1 Department of Natural and Applied Sciences, School of Science and Technology, The Glocal University, Mirzapur Pole, \\ Saharanpur, Uttar Pradesh- 247121 India \\ 2 Department of Chemistry, Aligarh Muslim University: Aligarh, Uttar Pradesh-202001 India \\ 3 School of Agricultural Sciences, The Glocal University, Mirzapur Pole, Saharanpur, Uttar Pradesh- 247121 India \\ * Correspondence: yusuf1020@gmail.com (M.Y.); mohd.yusuf@theglocaluniversity.in(M.Y.);
}

Scopus Author ID 57214875106

Received: 9.09.2021; Revised: 20.10.2021; Accepted: 24.10.2021; Published: 24.11.2021

\begin{abstract}
In the current era of eco-preservation, global research has focused on using raw and sustainable natural products with new clean technologies. New pharmaceutical or pharmaceutical agents from renewable sources are considered as essential as pure chemicals or certified fragments. A variety of natural phytoconstituents have been shown to reduce the risk of certain diseases and disorders, for example, diabetes, heart disease, cancer, neoplastic, and other health disorders. And, therefore, ongoing efforts to identify specific chemicals in these foods may contribute to their positive effects on beans/grains, fruits, vegetables, etc. Many of the phytochemicals that occurred as natural products in medicinal plants offer many opportunities in natural product research due to their versatile uses and various formulation. Curcuminoids are polyphenols found in the under-soil rhizome of Curcuma longa L. and have been used for centuries for spice, culinary, and food coloring purposes, and description also documented in the alternative system of medicines such as Indian Ayurveda, Sidha, Unani, and Chinese medicine system. It has been observed from the literature that the C. longa rhizome or commonly known as turmeric has several phytochemicals to possess anti-inflammatory, hepatoprotective, neuroprotective, antioxidant, anticancer, cardioprotective properties, and many more. The review highlights the recent progress of curcumin and its derivatives as promising bioactive and pharmaceutical agents with emphasis on future research dimensions required to propose curcuminoids as promising candidates for therapeutic and pharmacology-related sectors.
\end{abstract}

Keywords: curcuminoids; biological activity; curcumin; turmeric; pharmaceutical agents.

(C) 2021 by the authors. This article is an open-access article distributed under the terms and conditions of the Creative Commons Attribution (CC BY) license (https://creativecommons.org/licenses/by/4.0/).

\section{Introduction}

The hydrophobic bioactive ingredient, Curcumin (diferuloylmethane), is found mainly in the rhizome of $C$. longa. Owing to several biological and pharmacological actions, curcumin has obtained great attention amongst the scientific community working on natural products.

Curcumin is a pigment from the spice turmeric (Curcuma longa), found effective as a natural preservative and ingredient of common food items that belong to the Zingiberaceae family [1]. Turmeric is mainly composed of a group of three curcuminoids: curcumin (diferuloylmethane), demethoxy-curcumin, and bisdemethoxycurcumin, as well as volatile oils (tumerone, atlantone, and zingiberone) (Fig. 1), sugars, proteins, and resins[2]. About 2-8\% of turmeric by weight is curcumin. Curcumin and some of its analogs, fat-soluble polyphenolic pigments, are responsible for the vibrant yellow color of turmeric[3]. 
The chemical structure of curcumin was known way back in 1913, but biological properties of curcumin have been reported only in 1970s [4,5]. It contains diferuloyl methane moiety [1,7-bis (4-hydroxy-3-methoxy phenyl)-1,6-heptadiene-3,5-dione)] with two ferulic acid residues connected by a methylene bridge. The three main functional groups are the aromatic o-methoxy phenolic group, $\alpha, \beta$-unsaturated $\beta$-diketo moiety, and a seven-carbon linker[6]. Curcumin is a lipophilic polyphenol that is nearly insoluble in water [7] but is quite stable in the acidic $\mathrm{pH}$ of the stomach [8].

Turmeric is being consumed by the people of the Asia continent as a spice, preservative for various kinds of food items, and even as a remedy for many minor and major ailments forlong time. The interesting and exceptional medicinal properties of turmeric are also inscribed in ancient Indian literature. Several medicinal properties of turmeric attracted researchers to look into the therapeutic potential of its main constituent, Curcumin (CUR). It exhibits a wide range of fruitful biological properties[9,10]. Curcumin and its derivatives have shown strong antioxidant, free radical scavenging activities [11,12], anti-infectious [13,14], anti-inflammatory [15] and anticancer properties [16]. A schematic overview of turmeric is shown in Scheme 1, describing the biological properties of curcuminoids and derivatives (Table 1).

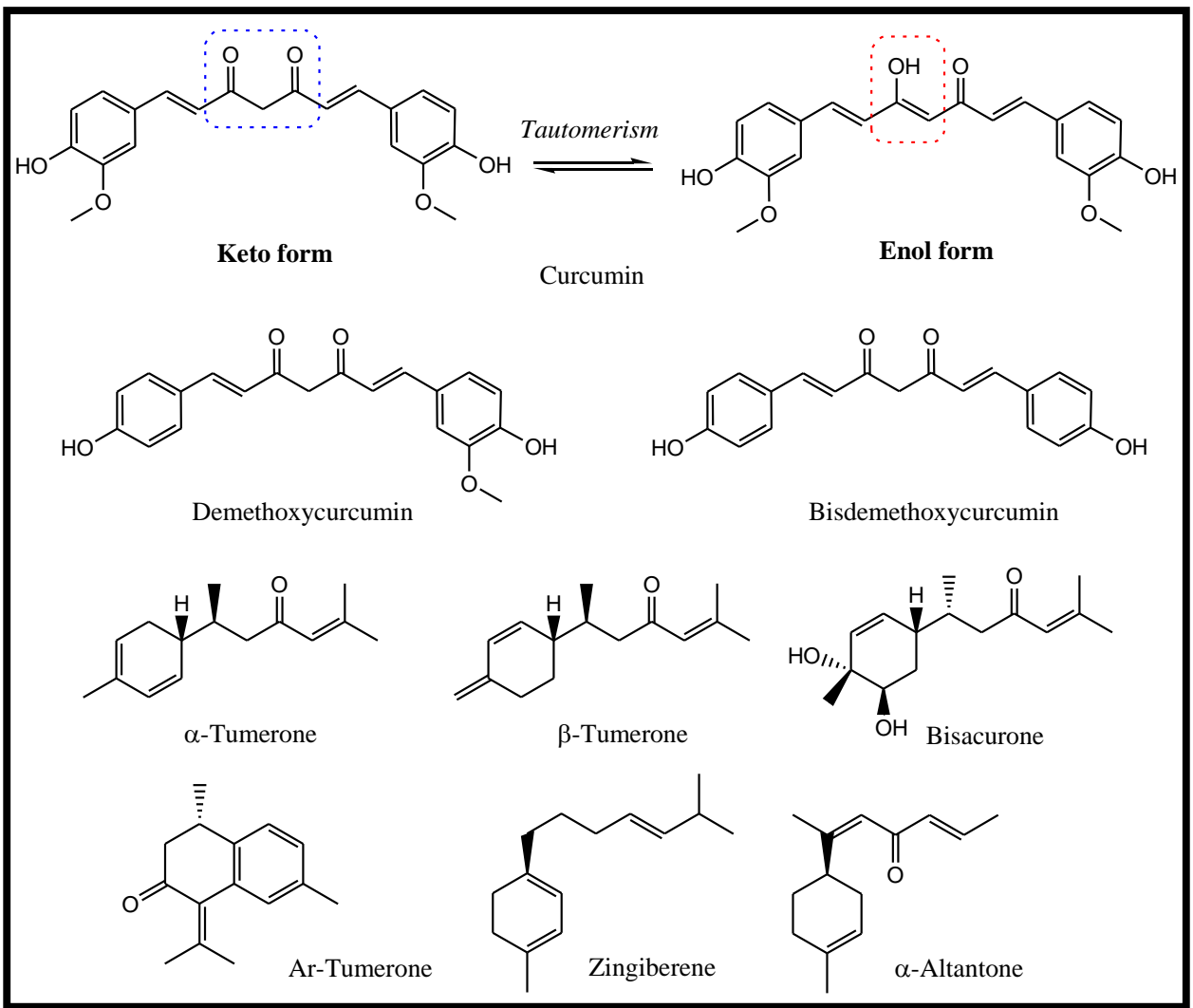

Figure 1. Chief phytochemicals reported in turmeric (phenolics/terpenoids).

Initially, the research was based on understanding its antioxidant role [17]. It took another way to identify its potential to interact with the transcription factor involved in the inflammatory response, nuclear factor-kappa $\beta$. This prompted researchers to pursue the antiinflammatory and anti-tumor effects of curcumin [18]. Previous studies proved that curcumin has chemo-preventive and therapeutic potential against varieties of cancers [10]. It inhibits different types of kinases, inflammation-promoting enzymes (cyclooxygenase and lipoxygenase), cytokines (IL-6, IL-8, and TNF- $\alpha$ ), and induces apoptosis in cancer cells[18]. 
In addition to its promising therapeutic potential against numerous chronic diseases, curcumin and its derivatives also exhibit to accelerate wound healing in cutaneous [15], excisional [19], and chronic wounds [20]. Curcumin has been known to target multiple signaling molecules, which indicates its activity at the cellular level and employs it in numerous health benefits[21]. It has also been shown to relieve metabolic syndrome [22], severe pain [23], and degenerative eye conditions [24]. In addition, it has the properties to benefit the kidneys[25]. Apart from its countless therapeutic benefits, most of the benefits are due to its antioxidant and antiinflammatory activities[26]. Also, it has been used by various folks to treat many diseases such as diabetes, Alzheimer's disease, and rheumatoid diseases [2].

Several forms of curcumin are available, including capsules, tablets, ointments, energy drinks, soaps, and cosmetics. Curcuminoids have been approved by the US Food and Drug Administration (FDA) as Generally Recognized As Safe (GRAS)[21]. Also, good tolerability and safety profiles have been exhibited by clinical trials, even at doses $4000-8000 \mathrm{mg} /$ day [27] and of doses up to $12,000 \mathrm{mg} /$ day of $95 \%$ concentration of three curcuminoids: curcumin, bisdemethoxycurcumin, and dimethoxy-curcumin [28]. The major challenges limiting the pharmaceutical and therapeutic feasibility of curcumin areits poor aqueous solubility, chemical instability, and low oral bioavailability, mainly due to its inadequate absorption in the blood, transmembrane permeation, and rapid metabolism (via conjugation - glucuronidation and sulfation) [26]. Even after administration in gram quantities, only a nanogram of curcumin is found in the plasma [29]. Also, photo-degradation is another limitation to effective CUR delivery [30]. In recent decades, several approaches have been employed to reduce pharmaceutical issues related to the productive delivery of CUR that includes micellar solubilization [31], cyclodextrin complexation [32], crystal modification (e.g., metastable polymorphs, salt formation, and amorphization), prodrug strategies and reduction of particle size. However, none of the strategies has been completely successful. Recently, nanotechnology-based approaches have gained attention due to their potential in increasing in vitro and in vivo activities of CUR [33]. Many agents have been tested to alleviate curcumin's bioavailability by addressing various mechanisms. For example, piperine, a known bioavailability enhancer, is the major active component of black pepper [34] and increases curcumin's bioavailability by $2000 \%$. Hence, the issue of poor bioavailability can be improved by adding agents such as piperine resulting in a curcumin complex [35].

The purpose of this review is to provide a brief overview of the research related to the therapeutic potential of curcumin and its derivatives with recent advancements. Due to the great extent of literature available, this review article specifically focuses on the anti-microbial, anticancer, anti-Alzheimer, anti-oxidant, anti-inflammatory, therapeutic effects against corona virus and neuroprotective applications of curcumin and its analogs. Over the next few years, numerous clinical trials are currently in progress that will provide an even deeper understanding of the therapeutic potential of curcumin.

\section{Biological Properties}

\subsection{Antimicrobial.}

The antimicrobial properties of curcumin can be improved by visible blue light. It disrupted the membrane of microbes by inhibiting ATPase activity which opened its way for application in clinical dermatology [36]. It also inhibits the proliferation of bacterial cells by restricting the cytokinetic Z-ring assembly from FtsZ protofilaments, which play critical roles 
in bacterial cytokinesis [37], membrane permeabilization [38], production of ROS and antioxidant depletion [39], and biofilm initiation [40]. Hydrogen bonding and charge delocalization are curcumin's two main physicochemical properties for promoting the interactions with the outer bacterial cell wall [41]. Also, Hydroxyl and methoxy groups present in the curcumin play a vital role in its antimicrobial properties. Curcumin exhibits antimicrobial activity in vitro against several microbes, including several pathogenic gram-positive bacteria, for example; Bacillus cereus, Bacillus subtilis, Staphylococcus aureus, Streptococcus mutans, Staphylococcus epidermidis and gram-negative bacteria for example; Escherichia coli, Pseudomonas aeruginosa, Yersinia enterocolitica, and Shigella dysenteriae and also against several funguses such as Aspergillus níger, Candida albicans, Penicillium notatum and molds [42]. Gram-positive bacteria represent significantly more sensitive to curcumin than gramnegative bacteria. In gram-negative bacteria, the penetration of hydrophobic antimicrobial compounds couldn't occur effectively due to the presence of hydrophilic lipopolysaccharides in its outer membrane [41].

Streptococcus pyogenes causes many life-threatening infections such as sepsis, rheumatic fever, and TSLS syndrome (toxic-shock-like syndrome).

The diffusion method was employed to compare the antimicrobial effects of curcumin and antibiotic ciprofloxacin against $S$. mutans and $S$. pyogenes. Minimal inhibitory concentration (MIC) demonstrated that curcumin reduced the growth of $S$. mutans and $S$. pyogenes with inhibition zones of $9.7 \mathrm{~mm}$ and $10.2 \mathrm{~mm}$, respectively. However, the inhibition zone of antibiotic ciprofloxacin was observed as $15.52 \mathrm{~mm}$ and $13.4 \mathrm{~mm}$ against $S$. mutans and S. pyogenes respectively.

Furthermore, curcumin has also been shown to inhibit the dental biofilm formation subsequently, dental carries formation [43]. The skin commensally and opportunistic pathogen Staphylococcus epidermidis, coagulase-negative Gram-positive bacteria, are the main causative agent of nosocomial infections and acne vulgaris. It can form new anti-biotic strains and biofilm on medical devices that require higher doses of antibiotics. Curcumin has synergistic effects with other phytochemicals. The synergistic combination of curcumin and cinnamaldehyde was discussed, and detected that it has an efficient antimicrobial potency against $S$. epidermidis and hinders biofilm growth. MIC of curcumin and cinnamaldehyde were obtained as $3.12 \mu \mathrm{g} / \mathrm{ml}$ and $15.62 \mu \mathrm{g} / \mathrm{ml}$, respectively. The fractional inhibitory concentration index (FICI) was reduced to half compared to FICI against a planktonic culture equal to 0.5 . It altered the membrane permeability for killing the bacteria as determined by $\beta$-galactosidase assay on E. coli ML-35p [44]. Also, the curcumin-loaded myristic acid microemulsions showed antimicrobial properties against $S$. epidermidis. The physiochemical properties of curcumin microemulsions were determined by interfacial tension, size distribution, and viscosity data of the microemulsions. The Dermal curcumin accumulation and transdermal curcumin penetration were observed at $326 \mu \mathrm{g} / \mathrm{g}$ skin and $87 \mu \mathrm{g} / \mathrm{cm}^{2} / \mathrm{d}$, respectively, which were analyzed using confocal laser scanning microscopy. The concentration of $0.86 \mu \mathrm{g} \mathrm{mL}^{-1}$ curcumin in the microemulsion could reduce $50 \%$ of the bacterial growth [45].

Due to curcumin's durability, curcumin dyed on cotton suppressed the growth of $E$. coli and Staphylococcus aureus, where the rate of inhibition was directly varied with the concentration of curcumin. However, it was observed that curcumin showed better antimicrobial activity towards $S$. aureus than $E$. coli. A very low concentration of curcumin, around $0.01 \%$, was required to inhibit $77 \%$ of $S$. aureus, while at least $0.1 \%$ of curcumin was 
required even to detect the inhibition of E. coli [46]. Hyperbranched epoxy/silver-reduced graphene oxide-curcumin nanocomposites were also employed to detect antimicrobial activity against $S$. aureus and $C$. albicans in surgical infection sites with minimum inhibitory concentrations of 38 and $41 \mu \mathrm{g} \mathrm{mL}^{-1}$ at $3 \%$ delivering of nanohybrid. The strong mechanical properties of nanocomposites were due to tensile strength of 54-65 MPa.

The investigations of nanocomposite curcumin determined that the amount of green microalgae Chlorella sp. also get reduced on its surface. Hence, it has acceptable antimicrobial potential in biomedical and marine applications [47]. The treatment of burn wounds is limited due to toxicity, insufficient penetration, and increasing agents' resistance. To tackle the poor aqueous solubility of curcumin, its encapsulation was done, which improved its activity in treating infected burn wounds. Its administration obstructed in vivo growth of Methicillinresistant S. aureus (MRSA) and Pseudomonas aeruginosa, which increased wound healing in vivo murine wound model. The CFU quantification concluded that curcumin nanoparticles caused a 97\% reduction of MRSA growth while 59.2\% reduction of $P$. aeruginosa [48]. To control the pre- and post-harvest Salmonella and E. coli food pathogens in poultry meat and avoid chlorine toxicity, safer compounds with minimal side effects were needed. It led to the promising potential of curcumin in inhibiting the growth of Salmonella and E. coli by assisting the macrophages and their ATPase activity which was examined by BacTiter-Glo ${ }^{\mathrm{tm}}$ Cell Viability Assay. It was found that the amount of ATP present in both the bacteria was reduced after the treatment with curcumin. The growth percentages of curcumin were inversely proportional to the concentration or doses of curcumin, and $100 \%$ of inhibition was observed at $200 \mu \mathrm{M}$ of Curcumin for both the bacteria [49].

\subsection{Anticancer.}

Cancer is considered globally as one of the major public health issues and the second leading cause of death. Despite the great advances in cancer therapeutics, there was not much difference in the mortality rate seen. In this context, several anticancer drugs/agents have been synthesized. Alternatively, due to better eco-friendliness, a number of naturally-derived compounds have been extracted from different plants such as Betula alba, Cephalotaxus species, Erythroxylum Pervillei, Curcuma longa, and many others. Among them, curcumin has received great intention due to its promising results in several different types of cancer, such as prostate, colorectal, breast, pancreatic, brain, head, and neck cancers[51]. The main mechanisms of action due to which curcumin exhibits efficient anticancer activity include promoting apoptosis and inhibiting proliferation and invasion of tumors by restricting the variety of cellular signaling pathways or intracellular transcription factors. These factors mainly include NF- $\mathrm{kB}$, activator protein 1 (AP-1), cyclooxygenase II (COX-2), nitric oxide synthase, matrix metalloproteinase-9 (MMP-9), and STAT3. Curcumin disturbs the balance in the potential of the mitochondrial membrane, which increases the suppression of $\mathrm{Bcl}-\mathrm{xL}$ protein leading to the improvement in apoptotic signals [52]. The anticancer properties of curcumin are mainly attributed to its structure. The modifications in the chemical structure of curcumin affect the binding of receptors and pharmacological property of a drug molecule and alter its pharmacokinetics and physiochemical activities. Dimethylcurcumin is one of the widely used curcumin analogs that enhances the degradation of androgen receptors and has applications in treating prostate cancer [53]. In addition to this, it has also shown a significant antiproliferative effect against estrogen-dependent breast cancer cells [54]. Although methylation has improved the targetability and activity of the molecule, it has also greatly 
increased its hydrophobicity compared to curcumin, which has limited its administrable dose in cancer therapy. Curcumin analogs were synthesized by modifications in the aryl side chains of curcumin, and their anti-cancer activities were analyzed. These compounds offered an impetus to anticancer strategies by reducing the growth of cultured BGC-823, SGC-7901, and MFC gastric cancer cells present in MTT assay [55]. Novel Aza-aromatic curcuminoids, i.e., the pyridine-, indole-, and pyrrole-based curcumin analogs, possess better biological activities towards various cancer lines in comparison to curcumin and bisdemethoxycurcumin. These compounds improve water solubility, antioxidant potential, and biological influences like mitochondrial activity [56]. The differential potency for inhibition of cancer cell invasion varied as BDMC > DMC > CUR. Zymography analysis showed that CUR, DMC, and BDMC significantly down-regulated urokinase plasminogen activator, active MMPs from the cells in a dose-dependent manner, in which BDMC and DMC showed higher potency than CUR. Three forms of curcuminoids significantly inhibited collagenase, MMPs. DMC and BDMC exhibited higher anti-metastasis potency than curcumin by differentially down-regulation of ECM degradation enzymes [57]. Based on natural proportions, integration effects of curcuminoids were studied by chemical markers' technique and metabolomics. By chemical markers' technique, the combination of $\mathrm{CU}$, curcuminoids (CE), BDMC, DMC having natural proportion possess synergistic anti-lung cancer activity on A549 cells, which resulted in the variations in 25 metabolites such as glycerophospholipid catabolism, sphingolipid metabolism, and fatty acid metabolism, etc. Moreover, CE group and BDMC, DMC greatly affected glycerophospholipid catabolism and sphingolipid metabolism, respectively [58]. RT-PCR and Western blot were implemented to reveal the reaction of CUR on HIF-1 $\alpha$ in cisplatin (DDP) sensitive A549 and resistant A549/DDP cell lines. Curcumin endorsing its usefulness as therapy for lung cancer which obstructed A549/DDP cells proliferation, reversed DDP resistance, and activated apoptotic death by operating HIF-1adegradationand inducing caspase-3, respectively [59].

Curcumin and resveratrol (derived from Polygonum cuspidatum) exhibited a combined anti-cancer effect in colon cancer by suppressing the proliferation of Hepa1-6 cells and increasing its intracellular reactive oxygen. This synergistic combination also inhibited XIAP and surviving expression, which was utilized as the anti-cancer strategy in treating liver cancer [60]. Curcumin has also improved the anti-cancer activity of Trichostatin A in SkBr3 and $435 \mathrm{eB}$ breast cancer cells by decreasing the phosphorylation of ERK and Akt and arresting G0/G1 cell cycle. It resulted in the up-regulation of protein expression of Bax and Bcl 2 and down-regulation of p53 activity, which was traced by JNK signaling pathway [61]. These compounds hinder the activity of Na-K-ATPase, which is the reason behind this synergy [62]. It was revealed that the Curcuminoids-PDT could be a novel therapeutic agent in the inhibition of breast cancer lines. DMC-PDT was employed as a photosensitizer in photodynamic therapy (PDT) which activated early autophagy and late apoptosis. The outcome of DMC-PDT treatment was the reversion of cell viability, decrease in LC3 conversion, and PARP cleavage. The cells were treated with $4 \mu \mathrm{M}$ DMC followed by blue light illumination leading to the formation of extensive vacuoles iDMC-PDT group at $24 \mathrm{~h}$ (Fig. 2A). As shown in Fig. 2B, DMC-PDT treatment elevated the conversion of LC3-I to LC3-II, and the maximum conversion was observed at $6 \mathrm{~h}$. Cells were stained with MDC to confirm the effect of DMCPDT on autophagosome formation. The increased number and distribution of spots could be observed in DMC-PDT (Fig. 2C). The conversion of LC3-I to LC3-II could be observed in the cells exposed to DMC with illumination but was not observed in those cells exposed to either 
DMC or illumination (Fig. 2D). This data represents that illumination is required for DMCinduced autophagy. It means that DMC-PDT induced autophagy in a light dose-dependent manner (Fig. 2E). This literature indicates that DMC-PDT induces the conversion of LC3-I to LC3-II, which plays an important role in autophagy [63].

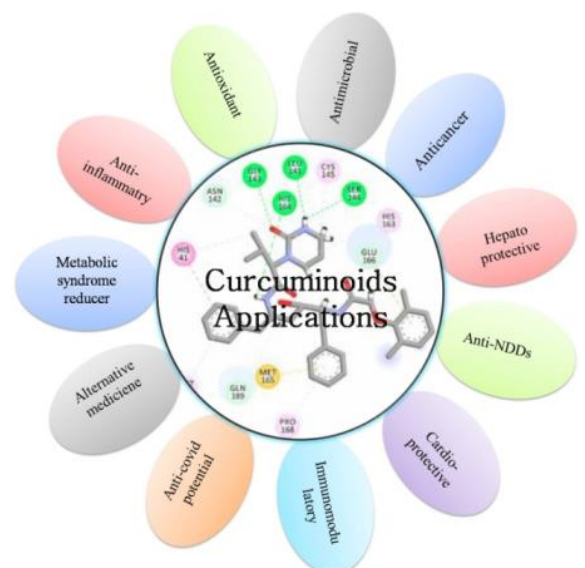

Scheme 1. Schematic overview of biological properties of Curcuminoids and their derivatives.

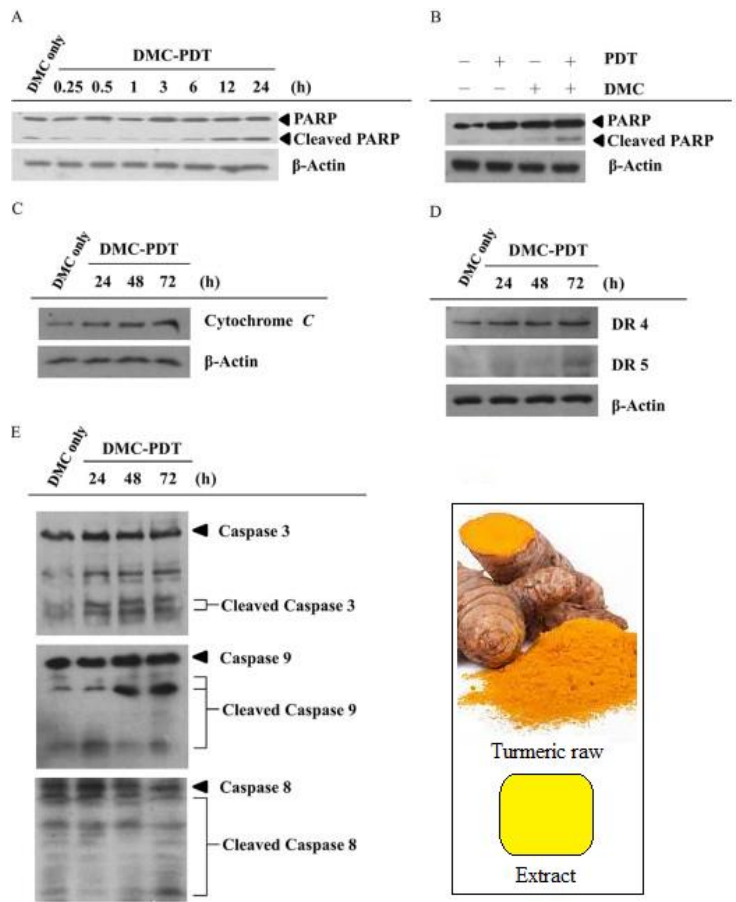

Figure 2. Effect of DMC-PDT on apoptosis in MDA-MB-231 cells. (A) The cells were treated with $4 \mu \mathrm{M}$ DMC with blue light and lysed at the indicated times. PARP cleavage was measured by Western blot analysis. (B) Cells were treated with $4 \mu \mathrm{M}$ DMC with or without blue light at $24 \mathrm{~h}$ incubation, respectively. The total lysates of cells were analyzed for PARP cleavage using Western blot analysis in the absence of DMC, in the presence of PDT alone, in the presence of DMC alone, or in the presence of DMC and PDT. (C) The cytosolic faction lysates were analyzed for cytochrome $\mathrm{C}$ on Western blot analysis after DMC-PDT. (D) The total cell lysates of cells were analyzed for DR 4 and DR 5 on Western blot analysis after DMC-PDT. (E) The total cell lysates were analyzed for caspase 3, caspase 9, and caspase 8 on Western blot analysis after DMC-PDT. $\beta$-Actin was used as the loading control. Reproduced with modification from Ref. [63] under the Creative Commons CC-BY-NC-ND license, Elsevier 2015; Inset: Schematic raw turmeric, powder, and extract.

Curcumin supplementation in patients with colorectal cancer was observed to decrease the M (1) G levels in the malignant colorectal cells without affecting the COX-2 protein levels. Moreover, it reduced the activity of the miR-21 gene by obstructing the binding of activator 
protein, i.e., AP-1, to the miR-21 promoter[64]. However, various nanoparticles have been formulated using different nanotechnologies to improve curcumin properties and targetability. Mucoadhesive particles have been observed to elevate the anticancer effect of curcumin in colorectal cancer. Curcumin-containing chitosan nanoparticles (CUR-CS-NP) were found to be effective in colorectal cancer cells. The in vitro effect of mucoadhesive interaction between nanoparticles and colorectal cancer cells and the ex vivo mucoadhesion of the nanoparticles were demonstrated. Curcumin-containing chitosan nanoparticles (CUR-CS-NP) have better mucoadhesion than chitosan nanoparticles (CS-NP) which showed that it is absorbed efficiently by colorectal cancer cells. The lowering in percentage cell viability, arresting cell cycle at $\mathrm{G}_{2} / \mathrm{M}$ phase, and $\mathrm{IC}_{50}$ indicated the effective mechanism for colorectal cancer treatment [65]. Poly (lactic-co-glycolic acid)-CUR nanoparticles (PLGA-CUR NPs) were also developed, leading to improved anticancer effects in tumor xenograft tissues. It suppressed the expressions of nuclear $\beta$-catenin and AR and also regulated the activity of miR-21 and miR205. Therefore, curcumin is a promising novel anticancer strategy for prostrate cancer [66].

\subsection{Anti-Alzheimer.}

Alzheimer's disease (AD), a progressive and chronic neurodegenerative disorder, affecting mainly the cortex and limbic system. Patients with AD show memory loss, cognitive and behavioral changes.AD is the major cause of dementia that leads to deterioration in thinking. The scopolamine-induced dementia models are considered most consistent in AD researches [67]. The introduction of $-\mathrm{CH}_{2} \mathrm{COOC}\left(\mathrm{CH}_{3}\right)_{3}$ group on the central atom of di-ketonic component of curcumin broughtabout the formation of $\mathrm{K} 2 \mathrm{~T}$ derivatives which improved its pharmaceutical applications [68]. The accumulation of extracellular amyloid plaques composed of $\beta$-amyloid (A $\beta$ ) peptides and intracellular neurofibrillary tangles (NFT) containing hyperphosphorylated tau protein are the pathological hallmarks of Alzheimer's disease[69]. The high levels of some metal ions like $\mathrm{Fe}^{3+}, \mathrm{Cu}^{2+}, \mathrm{Al}^{3+}, \mathrm{Zn}^{2+}, \mathrm{Hg}^{2+}$ and $\mathrm{Mn}^{2+}$ present in the brain bind strongly to the $\mathrm{N}$-terminus, metal-binding sites in $\mathrm{A} \beta$ peptides, and resulted in the accumulation of $A \beta$. It causes oxidative stress and neuronal cell death [70]. Due to curcumin's potent anti-inflammatory and antioxidant activities, it appeared to represent promising targets for the treatment of $\mathrm{AD}$. The number of in vitro and in vivo studies proved that curcumin exhibits anti-amyloid activity [71]. Curcumin binds to the non-polar regions of the $A \beta$ oligomers by hydrophobic interactions, which prevented the aggregation of $A \beta$ and down-regulated the toxicity of the $A \beta$ oligomer. Curcumin also has acceptable metal-chelating properties, due to which it binds to the metal ions present in the brain and form stable complexes which prevent the $\mathrm{A} \beta$ aggregation. As a result, it reduces the formation of peptidemetal complexes [72]. It was reported that strong interaction exists between curcumin and metal ions in curcumin-metal complexes where metal ions can be $\mathrm{Cu}^{2+}, \mathrm{Al}^{3+}$, and $\mathrm{Hg}^{2+}[73]$. Several imidazole-containing curcumin analogs were synthesized and could be a useful candidate as an inhibitor that can reduce the crosslinking of $\mathrm{A} \beta$ induced by $\mathrm{Cu}^{2+}[74]$. The oxygen radical absorbance capacity (ORAC) method and a cell-based assay using DCFH-DA revealed that the synthesized metal complexes of the curcumin had a higher inhibitory effect against deposition of amyloid- $\beta$ than curcumin. It decreases metal-induced amyloid- $\beta$ deposition by chelating metals such as iron, manganese, and copper, which was observed by various spectroscopic and analytical methods, such as elemental analysis, TG, AAS, FT-IR, etc. The results strongly encouraged the synthesis of the curcumin-iron complex for enhancing memory and their acceptable latent period values [75,76]. Administration of scopolamine leads 
to the degeneration of Akt and GSK-3 $\beta$ phosphorylation in the hippocampus, responsible for memory loss. Curcumin reverses the hallmarks of Alzheimer's disease and prevents these changes [77]. As compared with curcumin, the loss of cholinergic neurons can be controlled competently by probiotic Lactobacillus rhamnosus.

Consequently, curcumin with probiotics strengthened the memory and antioxidant system [78]. The mouse model of APP/PS1 and wild-type (WT) C57BL/6J of Alzheimer's disease has been used for studying these symptoms on curcumin's administration. The memory improvement was observed in the curcumin-treated mice-elevation in lactate content, as well as MCT2 protein in the cerebral cortex and hippocampus, were determined. Supplementation of curcumin improved the supply of lactate, which ameliorated the memory function of APP/PS1 mice. The two analytical techniques, i.e., western blotting and immunochemistry, were used to examine MCT2 expression in the cerebral cortex and hippocampus [79].

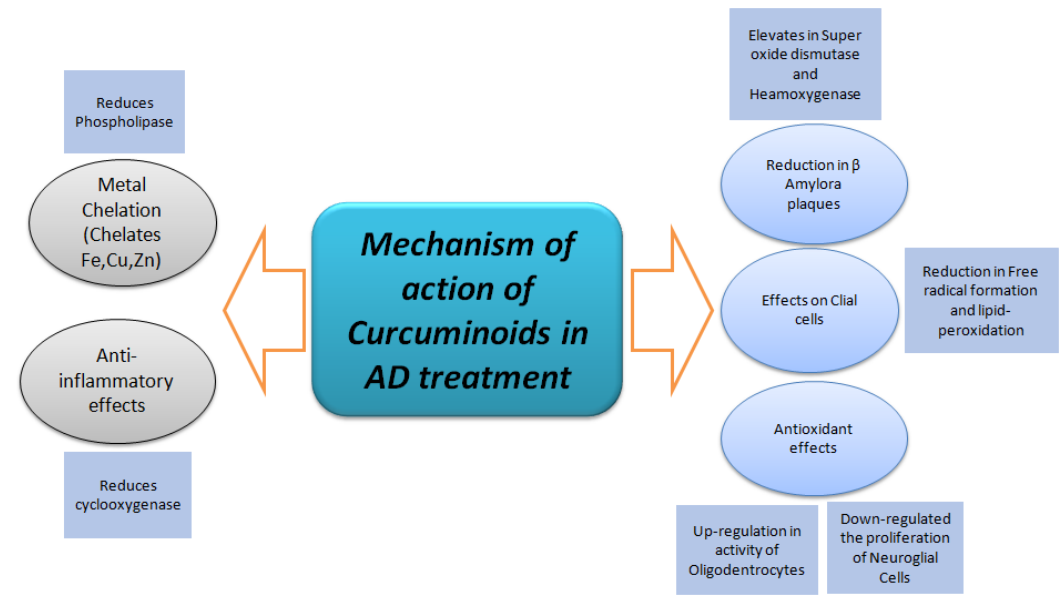

Scheme 2. Various pathways of action of curcuminoids in Alzheimer's disease (AD) treatment.

To overcome the problem of curcumin's low solubility, polymeric nanoparticle encapsulated curcumin (NanoCurc) was synthesized. Aggregation of amyloid- $\beta$ plaques reacts with activated microglia, which contributes to reactive oxygen species (ROS) production. Curcumin's administration reduced the levels of $\mathrm{H}_{2} \mathrm{O}_{2}$, actions of pro-apoptotic enzyme 3, and caspase 7 in the brain, which was accompanied by an increase in the concentration of glutathione. NanoCurc protected the viability of differentiated human neuroblastoma (SK-N$\mathrm{SH})$ cells from ROS in a dose-dependent manner. So, curcuminoids analogs appear to be more beneficial as anti-Alzheimer agents [80]. Scheme 2 depicts curcuminoids' various accepted pathways of action in Alzheimer's disease (AD) treatment [8,72-76]. Eight dimethylaminomethyl-substituted curcumin derivatives were synthesized and evaluated as potential agents for the treatment of AD. Their properties were determined by the oxygen test. It showed that compound (A) (Fig. 3) had better inhibitory properties against the accumulation of $\mathrm{A} \beta$ than lead compound curcumin. In addition, compound (A) exhibited higher stability in phosphate-buffered solution in the presence or absence of $0.1 \% \mathrm{FBS}$ (at $\mathrm{pH}=7.4$ ) and showed capability to penetrate the blood-brain-barrier [81].

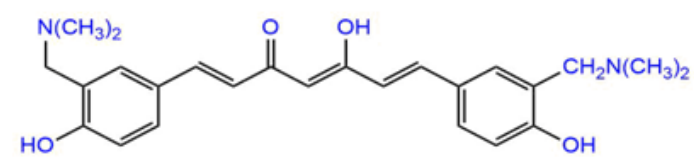

Figure 3. Chemical structure of dimethylaminomethyl-substituted derivative of curcumin (auxochromes are presented in blue color). 


\subsection{Antioxidant and anti-inflammatory.}

Curcuminoids, a phenolic antioxidant which wereobserved by NMR analysis. Curcumin (CUR) and its two derivatives, i.e., bis-demethoxycurcumin and demethoxycurcumin, exhibit antioxidant activity due to its $\cdots \mathrm{CH}_{3} \cdots \mathrm{H}-\mathrm{O}$ hydrogen bonds, which were extracted from curcumin longa [82]. The compound consists of seven curcuminoids, and chalcones were synthesized, and it was observed that antioxidant potential depends on the phenolic group at ortho and/or para position. Hence, o-substituted methoxy functionalization only increased antioxidant potential when the methoxy group was not bonded to the $\beta$-diketone moiety as a proton acceptor. The more phenolic nature of the compound indicates more antioxidant activity [83]. The free radical reaction centers of curcumin were due to the presence of two phenolic groups and the enol form of the diketone moiety and extended conjugated structure [74].

Curcumin is also reported to be an effective oxidative stress blocking agonist through multiple pathways. Curcumin inhibited the unregulated DNA damage by promoting Akt and MAPK pathways. It also stimulated the activities of several antioxidant enzymes, including SOD, catalase, GPx, GST, GR, and iNOS enzymes. However, it restricted the processes which are caused by the rotenone or paraquat and are responsible for causing oxidative stress. These processes involved the inhibition of $\mathrm{Nrf2}$, NFKB translocation in the cytosol, and the degradation of $\mathrm{IKB}$, hence exerting the antioxidant activity in the body. It leads to research on other formulations of curcumin to enhance the bioavailability of curcumin [84]. Micelles as a novel carrier system cause 70- and 180-fold increase in curcumin plasma as compared to free curcumin[85].

As single curcuminoids are less soluble, the antioxidant activities of compounds of curcuminoids were determined using Ferric-reducing power (FRAP assay) and ABTS assay, which has critical importance in reducing ABTS radical cation. The antioxidant properties of isolated curcuminoids varied as phospholipid complexquercetin $>$ trolox $>$ curcuminoids $>$ curcumin-cyclodextrin complex > curcumin [86]. Bisdemethoxycurcumin (BDMC) has better free radical scavenging ability in erythrocytes and good redox activity comparative to curcumin. All the parameters (SOD, MAD, diet, excreta, etc.) returned close to baseline levels after treatment with curcumin and bisdemethoxycurcumin by activating the Nrf2 signaling pathway [87]. BDMC inhibits oxDL uptake, which is responsible for fatty streaks in atherosclerosis, and CUR inhibits CD36, scavenger receptor A [88].

Furthermore, curcuminoids were co-administered with piperine at the dose of $1000 \mathrm{mg} /$ day and $10 \mathrm{mg} /$ day, respectively, for 8 weeks in the patients suffering from type II diabetes mellitus (T2DM). Additionally, it was concluded that it inhibited oxidative species and elevated antioxidant activities, which restricted diabetic issues [89]. Since encapsulation of curcuminoids improves the antioxidant and cytotoxic activity in an aqueous medium, it was performed to reduce the in vitro activity of two enzymes, i.e., acetylcholinesterase (AChE), a neurotransmitter, and glutathione S-transferase (GST) and cytotoxic effects against non-tumor and tumor cell lines [90]. Many studies have demonstrated that the curcumin metal complexes have better antioxidant activity as compared to free curcumin. It was observed that metal complexes of curcumin with several divalent metals such as $\mathrm{Cu}^{2+}, \mathrm{Fe}^{2+}, \mathrm{Mn}^{2+}, \mathrm{Mg}^{2+}, \mathrm{B}^{2+}, \mathrm{Se}^{2+}$, and $\mathrm{Zn}^{2+}$ improved their antioxidant activity [91].

Curcumin increased the expression of antioxidant genes and proteins, heme oxygenase 1 (HO-1), glutamate-cysteine ligase (GCL), and quinine oxidoreductase 1 (NQO1), but only in 
$\mathrm{Nrf} 2+/+$ cells [92]. It inhibited the $\mathrm{H}_{2} \mathrm{O}_{2}$-induced activation of transient receptor potential melastatin-like 2 (TRPM2) and hence decreased the TRPM2 protein levels. It also downregulated the levels of ROS in transfected cells and non-transfected cells. It was concluded that curcumin reduced apoptosis and inhibited oxidation via the TRPM2 channels[93]. Jonathan Ibrahim evaluated oxidative stress and antioxidant parameter in $\mathrm{CCl}_{4}$ injured rats treated with curcuminoids. Higher levels of aspartate transaminase, alanine transaminase, alkaline phosphatase, and lower levels of super oxide dismutase, glutathione, catalase caused increased oxidative stress in the patients with liver diseases such as liver cancer, cirrhosis, which could be controlled by supplementing the drugs of curcuminoids. Its administration elevated the concentrations of total proteins and albumins [94]. Oxidative stress is an emerging component of osteoarthritis. Supplementation with curcuminoid-piperine combination significantly enhanced serum activities of superoxide dismutase (SOD) as well glutathione (GSH) and reduced the concentrations of MDA as compared with placebo, which in turn improved oxidative status in patients with osteoarthritis [95]. Curcuminoids-piperine combination has also been proposed as a feasible approach to preventing metabolic syndrome (MetS), and it does wonder to the oxidative as well inflammatory complications which are the components of MetS [96].

Several studies have proved that curcumin can be utilized as a promising antiinflammatory agent. It was reported that curcumin had pronounced anti-inflammatory properties on activated microglia, macrophages present in CNS, by bringing down the activity of the PI3K/Akt signaling pathway, which in turn inhibited LPS-induced inflammatory responses. Anti-inflammatory properties of curcumin are attributed to suppression of prostaglandin synthesis and inhibition of COX2, LOX, iNOS, cytokine production, and transcription factors [97]. Several studies proved that curcumin can prevent COX2 expression [98]. Dimethyl-amino curcuminoid derivatives were found to be more potent antiinflammatory agents than parent CUR [99]. Curcumin supplementation effectively mitigates inflammation in patients suffering from chronic lung injury and cutaneous complications caused by exposure to sulfur mustard. It down-regulated the cytokines through the ERK pathway [100,101]. Atherosclerosis is an inflammatory response of the arterial wall to the injuries promoted by risk factors such as dyslipidemia, diabetes, hypertension, and others. Inflammation plays a critical role in all the stages of atherosclerosis. Therefore, curcumin was employed to reduce the inflammatory conditions. It regulated the cholesterol transport homeostasis and inflammatory response in M1 macrophages [102]. It was also reported to increase thrombospondin-4 (THBS-4) in mouse macrophages treated with oxidized lowdensity lipoprotein. There is evidence representing the regulating effects of curcumin on macrophage chemoattractant protein-1 (MCP-1), which is involved in the pathogenesis of several inflammatory diseases, for example, atherosclerosis [103].

Moreover, it was demonstrated that curcumin could be effective in patients with diabetes-related atherosclerosis [104]. The controlled mean pulmonary artery pressure resulted in the improvement of chronic obstructive disease (COPD) condition. It could be done by reducing the number of smooth muscle cells, which facilitated this goal. Curcumin promotes apoptotic cell death in smooth muscle cells by upregulation and down-regulation of BAX and Bcl-2, respectively. It inhibits the JAK2/STAT3 signaling pathway, which is influenced by the expression of SOCS-3 [105].

Curcumin was shown to be able to protect human synovial fibroblast cell line MH7A and fibroblast-like synoviocytes (FLS) by preventing both IL-1 $\beta$ and PMA-induced IL-6 
expression in patients who have rheumatoid arthritis (RA). Curcumin's inhibition of NF- $\mathrm{kB}$ and persuading dephosphorylation of ERK1/2 play a significant role in reducing chronic inflammatory symptoms like RA [19]. Also, it could serve as a proper tool for curing chronic asthma [106]. It was proved to be a promising therapy for diabetes by reducing oxidative stress and producing inflammatory cytokines. It improved the symptoms of vascular inflammatory diseases by obstructing the release of high mobility group box 1 (HMGB1) by lipopolysaccharide and the surface receptor of the cell for HMGB1 present in human endothelial cellscytokines[107]. It was investigated that CUR has an anti-inflammatory effect in the Mdr1a-/- mouse model of human inflammatory bowel disease by enabling $\alpha$-catenin. Its anti-inflammatory activity was verified by multiple molecular pathways, reduced immune response, higher xenobiotic metabolism, and elevated barrier modeling. The 2D gel electrophoresis and LCMS protein recognition were utilized for evaluating the level of the colon mRNA transcript. In this literature, colon RNA from four Mdrla-/- mice on the control diet [(high colon histological injury score (HIS)] and colon RNA from four FVB mice on the control diet (low colon HIS) was compared. Colon RNA from four Mdr1a-/- mice on the AIN76A diet (selected for high colon HIS) was compared with colon RNA from four Mdr1a-/mice based on curcumin-supplemented diet (selected for lower colon HIS). [108]. Antiinflammatory effects of CUR and Solid lipid CUR particles (SLCP) in vitro and in vivo 5xFAD models of Alzheimer's disease proved that SLCP exhibits more anti-inflammatory response than CUR due to greater reduction misfolded A $\beta$ aggregation [109]. Anti-inflammatory responses of synthesized mono-carbonyl analogs of curcumin were proposed in the mouse RAW264.7 macrophages which down-regulated LPS-induced secretion of TNF- $\alpha$ and interleukin-6 [110]. Liposomal formulations of CUR and curcuminoid increase their antioxidant and anti-inflammatory activities, which are employed as a chemopreventive in treating vaginal inflammation. Results of the HPLC technique showed their anti-inflammatory potential and resolution by analyzing the inhibition of lipopolysaccharide-induced nitric oxide, interleukin-1ßand TNF-aproduction in macrophage RAW 264.7 cells [111].

\subsection{Neuroprotective aspects.}

Neurodegenerative diseases (NDDs) are the second leading cause of deaths globally and becoming significant global health burdens. Amongst all the NDDs AD (discussed above) has a lethal factor of the largest severity. Most NDDs, including Huntington's disease (HD), Parkinson's disease (PD), hippocampal injury, amyotrophic lateral sclerosis (ALS), and prion diseases, remain essentially incurable. They all have almost similar pathological mechanisms characterized by amyloid protein aggregation in intra or extracellular matrices. Numerous factors including neuroinflammation, aging, oxidative damage and aggregated fibrillar protein deposits, resulting in age-related gradual decline in the neurological function leading to the cell death [112]. Curcumin crosses the blood-brain barrier and is neuroprotective in various neurological disorders. It has been reported to provide neuroprotection and regulate biochemical pathways caused by the symptoms of neurodegenerative disorders. Parkinson's disease is an age-associated neurodegenerative disorder that is characterized by the reduction in substantia nigra (SN), showing the symptoms, specifically stiffness, tremor, slowness of movement, and postural instability. Iron catalyzed the formation of highly toxic free radicals via the Fenton reaction leading to cell death. The pathogenetic processes of PD lead to severe damage to the hippocampus in the cerebral region, which leads to memory loss. 
Curcumin has the potential to bind with $\alpha$-synuclein restricting its aggregation and thus might be a novel therapeutic approach to treat Parkinson's disease (PD)[113]. Its therapeutic potential was explored in a 6-hydroxydopamine-lesioned rat model of PD both in vitro and in vivo. In this model, rats were initially treated with curcumin for 24 days, and after that6hydroxydopamine (6-OHDA) lesioning was conducted on day 4 of curcumin treatment. It protected substantia nigra neurons and improved striatal dopamine levels through HPLC assay with electrochemical detection. Curcumin reduced the toxic effects of (6-OHDA) on the SNstriatum system. It attenuated the oxidative stress due to its iron-chelating properties and suppressed the tyrosine hydroxylase $(\mathrm{TH})$ containing immunoreactive neurons, which was analyzed by immunohistochemistry [114]. Using HPLC, it was observed that curcumin prevented hippocampal injury prevention. As shown in Western blot analysis, curcumin increased dopamine and norepinephrine contents in hippocampal homogenate and operated BDNF/TrkB-dependent pathway for maintaining the neuron survival (BDNF:Brain-derived) neurotrophic factor) [115]. CUR has potential as an effective neuroprotective therapy in arsenic-induced cholinergic dysfunctions in brains. Its protective effect may be attributable to regulating oxidative stress, neurotransmitter, and dopamine levels. Compared to only arsenictreated rats, the result demonstrated better learning and memory performance due to higher binding of 3H-QNB and improved acetylcholinesterase's activity in the hippocampus and frontal cortex with the treatment of curcumin as well (100 mg/kg body weight, p.o., 28 days). The supplementation of both arsenic and curcumin was shown to improve the immunoreactivity and expression of choline acetyltransferase, staining of Nissl body in the hippocampal region [116]. It also protected ketamine-induced bipolar disorder (BD), the psychiatric disorder, by modulating behavioral and oxidant damage during mania episodes. Treatment with the curcumin ( 20 and $50 \mathrm{mg} / \mathrm{kgfor} 14$ days) increased the activity of the two antioxidant enzymes, i.e., superoxidase dismutase and catalase, in the hippocampus [117].

CUR has long been advocated for the treatment of traumatic brain injury (TBI). It regulated the Nrf2 pathway, which was assessed by Western blot and qRT-PCR after 24hrs of treatment. Its effect is associated with reducing ipsilateral cortex injury, neutrophil infiltration, and microglia activation, promoting neural regeneration against TBI-induced apoptosis [118].

To overcome the problems of less bioavailability and less drug concentration in the brain, nanotechnology has modified the surface of nanocarriers to elevate their delivery to the brain. Various nanocarriers like liposomes, magnetic nanoparticles, lipid nanoparticles, miscellaneous nanocarriers, polymeric micelles, and polymeric nanoparticles were employed to improve curcumin delivery to the brain in the treatment of several neurodegenerative disorders[119,120].

Lipid nanoparticles are preferred over other nanocarriers due to their number of properties such as high encapsulation, lipophilic nature, drug targeting, etc. Curcumin-loaded PLGA nanoparticles (cur-NPs) crossed the blood-brain barrier and increased the concentration of curcumin in the brain. It was reported that Curcumin nanocarrier $(\mathrm{CN})$ containing $\mathrm{D}-\alpha-$ tocopherol polyethylene glycol 1000 succinate (TPGS) and Pluronic F127 used as a candidate neuroprotective drug for the patients of glaucoma and other eye diseases. Administration of $\mathrm{CN}$ twice-daily for three weeks increased the solubility of curcumin up to $4.5 \mathrm{mg} / \mathrm{ml}$. In return, it helped in down-regulating the loss of retinal ganglion cells (RGCs) in the rat models of optic nerve disease, ocular hypertension (OHT), and partial optic nerve transection (pONT) [121]. 
Table 1. The potential of curcuminoids and their derivatives in various biological activities.

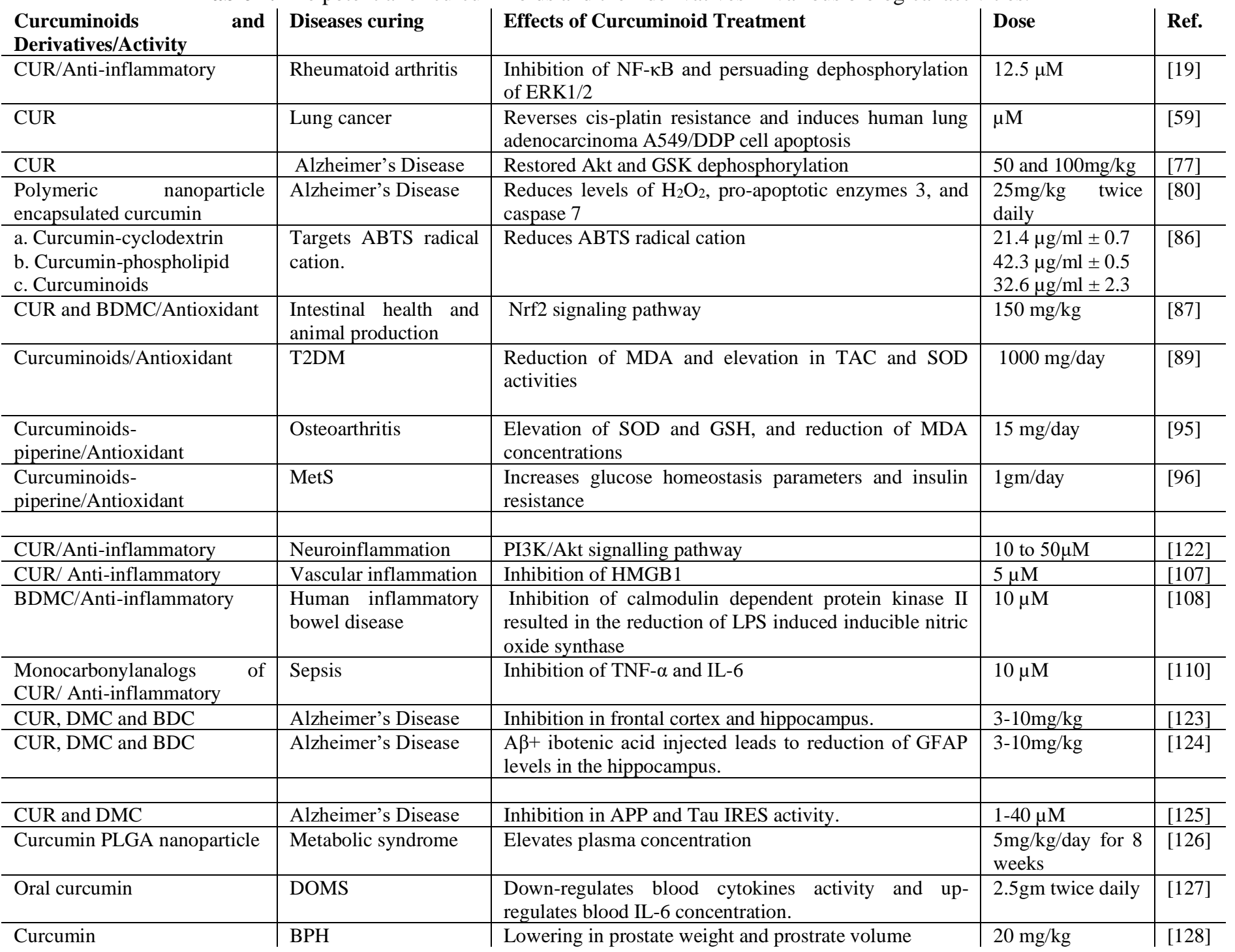

\section{Therapeutic Effects of Curcuminoids Against COVID-19}

In December 2019, a novel deadly corona virus emerged in Wuhan, China, caused by the Severe Acute Respiratory Syndrome Corona Virus-2(SARS-CoV-2) and spreads worldwide. It is one of the most alarming pandemic outbreaks in the $21^{\text {st }}$ century [129]. Several drugs are prescribed to patients, but no current effective antiviral drug has minimal side effects. During this scenario, various studies have discussed the therapeutic potential of curcumin and its mechanism in the treatment of the corona virus [130]. Curcumin plays a major role against a number of viruses such as influenza A virus, Human Immunodeficiency Virus (HIV), enterovirus 71 (EV71), herpes simplex virus (HSV), hepatitis C virus (HCV), Chikungunya virus, Ebola virus, and human papillomavirus (HPV) with numerous mechanisms which made it valuable for antiviral therapies. Due to the broad-spectrum and low toxicity of curcumin, it can be used as an antiviral agent against SARS-CoV-2 [131]. Curcumin can regulate the number of molecular targets, which play a major role in viral infections. The molecular targets could be summarized as(i) transcription and replication regulation [132], (ii) obstruction of proteases (iii) obstruction of attachment and virus entrance into the cells [133] (iv) inactivation and attack of the virus's structures [134]. In silico, preliminary studies have been performed to examine various medical plant compounds as inhibitors for SARS-CoV-2 main protease $\left(\mathrm{M}^{\mathrm{pro}}\right)$, 
which plays an essential role in the viral multiplication and can represent potential targets for the treatment of COVID-19.

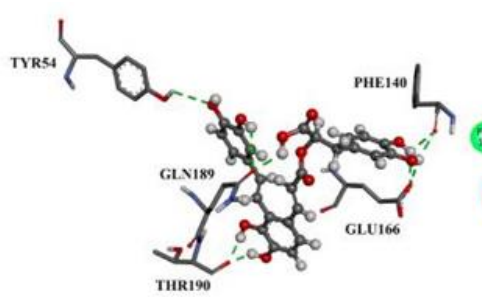

(a)

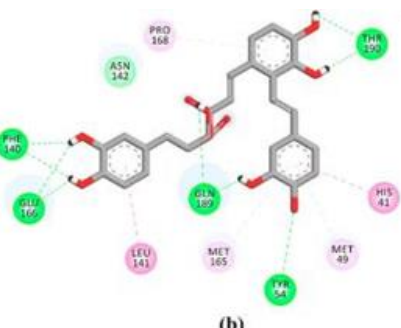

Docking results of (i) Salvianolic acid A: (a) 3D Docking and (b) Bonding interactions

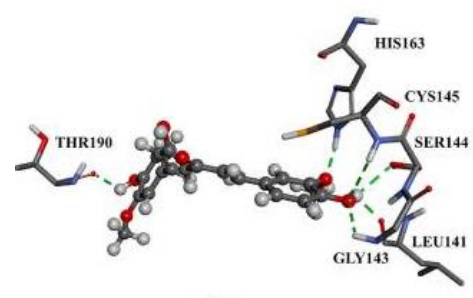

(a)

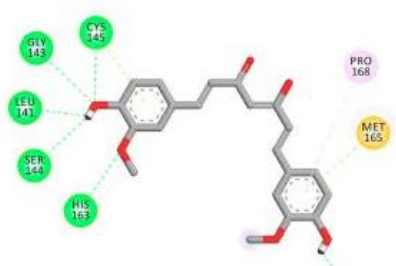

(b)

Docking results of (ii) curcumin: (a) 3D Docking and (b) Bonding interactions

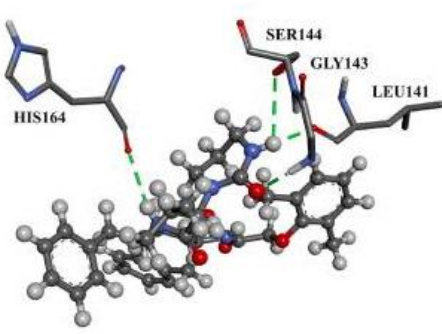

(a)

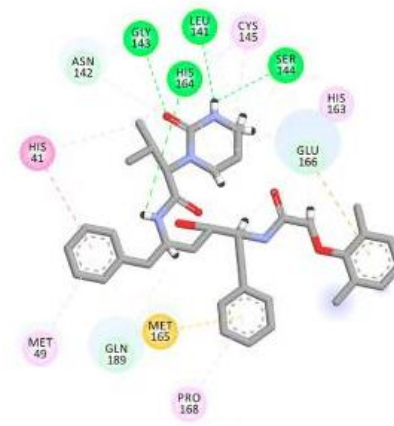

(b)

Docking results of (iii) Lopinavir: (a) 3D Docking and (b) Bonding interactions

\section{Interactions}

$\square$ van der Waals
$\square$ Carbon Hydrogen Bond
Conventional Hydrogen Bond
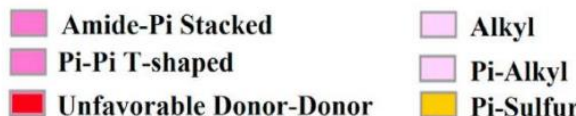

Figure 4. Lopinavir, a peptidomimetic molecule showing antiretroviral protease inhibitor action against HIV and COVID-19 virus. Lopinavir exhibited high binding affinity $(-9.8 \mathrm{kcal} / \mathrm{mol})$, forming four hydrogen bonds with HIS164, SER144, LEU141, and GLY143 with bond lengths of 2.62, 3.09, 1.96, and 2.01 $\AA$, respectively). A docking comparison of lopinavir with salvianolic acid A and curcumin revealed competing binding affinities suggesting the in silico potentiality of the three compounds as $\mathrm{M}^{\mathrm{pro}}$ inhibitors. Reproduced from Ref.[135] under open permission WHO-COVID database with rights for unrestricted research re-use and analyses, Elsevier 2020.

Using docking calculations, it was observed that curcumin has a high potency as

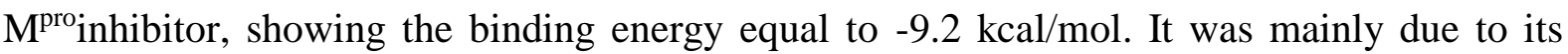
capability to form six hydrogen bonds with the bond lengths ranging from 1.90 to $2.85 \AA$, hydrophobic and pi $(\pi)$-based interactions, van der Waals interactions with the amino acids near to $\mathrm{M}^{\text {pro's }}$ active site. The scheme showing the interaction between the curcumin and amino acid residues of SARS-CoV-2 viral protein is shown in Fig. 4 [135].

Instead of its biological benefits and potential as a medication in treating COVID-19 due to its inhibition of SARS-CoV-2 viral pathways, curcumin's physiochemical activities reduce its bioavailability. Some of the prominent physiochemical activities are poor water solubility, which is around $11 \mathrm{ng} / \mathrm{ml}$, low stability in aqueous media, especially in alkaline $\mathrm{pH}$. 
It has shown that the transformation of curcumin into nanosystems could boost its solubility, transport through biological membranes, and protect drugs from chemical and metabolic degradation [136]. During this pandemic of COVID-19, only a few nanotechnological curcumin-based products are available in the market, mainly in the form of polymeric nanoparticles (Nanocurc ${ }^{\mathrm{TM}}$ ), liposomes (Lipocurc ${ }^{\mathrm{TM}}$ ), and nanomicelles (Sinacurcumin ${ }^{\circledR}$ ) [137].

In vivo study highlighting the efficiency of curcumin-loaded nanosystems against COVID-19 was conducted by Saber-Moghaddam and collaborators [138]. They concluded that the nano-formulation of curcumin (Sinacurcumin ${ }^{\circledR}$, a soft gel capsule containing $40 \mathrm{mg}$ of curcuminoids in nanomicelles) with a dose of $80 \mathrm{mg}$ twice daily was able to reduce most of the symptoms in patients with mild and moderate COVID-19. The improvement in the recovery time and lymphocyte count after 7 to 14 days was also observed [138]. In this study

Saber-Moghaddam et al. observed a $p$-value based on Fisher's exact test for lungs CT 0.332 whereas found 0.996 for TT-PCR [138]. A randomized, double-blind, placebo-controlled study was conducted to evaluate the effects of Sinacurcumin ${ }^{\circledR} 40 \mathrm{mg}$ on the regulation of inflammatory cytokines in COVID-19 patients with a dose of 4 capsules daily for 14 days. The expression of mRNA and levels of cytokine secretion of IL-1 $\beta$, IL-6, TNF- $\alpha$, and IL-18 were determined by Real-time PCR and ELISA, respectively. It was concluded that Sinacurcumin ${ }^{\circledR}$ up-regulated the rate of inflammatory cytokines, especially the IL-1 $\beta$ and IL-6 mRNA expression and cytokines secretion in patients with COVID-19, which can improve the inflammatory condition of patients [139].

Despite several positive conclusions from the in vivo studies of Sinacurcumin ${ }^{\circledR}$ in the treatment of COVID-19, this formulation mainly focuses on controlling the symptoms and regulating the inflammatory responses. It was observed that other nano-systems have many advantages like easy cell uptake, higher permeability, biodegradability, etc., and nanoparticles mainly exhibit the advantages of easy customization and functionalization. The replication of SARS-CoV-2 is a complex process involving synthesizing RNA, proofreading, and capping [140]. It was observed that curcumin-loaded silver nanoparticles (AgNPs) enhanced the antiviral activity compared to curcumin. Curcumin-AgNP disrupted the replication of SARSCoV-2 by attaching to the viral DNA or RNA, inhibiting the virus replication inside the host's cells [141]. In addition to this, curcumin-carbon dots were synthesized, which can repress the entrance of virus into the cell and the viral-RNA of porcine epidemic diarrhea virus (Coronaviridae family) [142].

SARS-CoV-2 is a beta-coronavirus which develop severe pneumonitis. The inflammation in COVID-19 pathogenesis has resulted from up-regulation in the levels of inflammatory cytokines (TNF, IL-1 $\beta$, IL-6, IL-8), colony-stimulating factors (G-CSF and GMCSF), and inflammatory chemokines (MCP1, IP10, and MIP1 $\alpha$ ) and destruction or downregulation in the levels of inflammatory monocytes and macrophages [143]. It was studied that the TGF- $\beta$ can be a good therapeutic target for COVID-19. It was observed that curcumin plays a significant anti-inflammatory role in the patients with COVID-19 by controlling the cytokineinduced damages. It represses the activity of interleukin-6 (IL-6) by down-regulating the STAT3 [144]. Also, it inhibits the TGF- $\beta 1$ and decreases the production levels of proinflammatory cytokines such as TNF- $\alpha$ and MPC-1[145].

Inflammasomes are one of the most important components of innate immunity, which worsen inflammation by increasing the production of IL-1 $\beta$, IL-18, and gasdermin D [146]. The direct and indirect activation of inflammasome caused by the proliferation of SARS-CoV- 
2 in the number of cells. Its activation causes severe cytokine storm and acute respiratory distress syndrome (ARDS), leading to death. Curcumin stimulates nuclear factor erythroid 2related factor 2 (NRF2), a transcription factor, which in turn obstructed the activity of NLRP3 inflammasome as a basic signaling complex in exacerbating inflammation. Most of the COVID-19 patients suffered not only lymphopenia but also a phenomenon called $\mathrm{T}$ cell exhaustion. Curcumin has proved its capability to inhibit the loss of $\mathrm{T}$ cells, which enhances effector memory $\mathrm{T}$ cell populations and also decreases the suppressive activity of Treg cells by down-regulating the TGF- $\beta$ and IL-10 synthesis. It was also reported that curcumin improved the paraquat (PQ) (N, N'-dimethyl-4,4'- bipyridinium dichloride) induced acute lung injury (ALI) by inhibiting NLRP3 inflammasome and restricting the increment in the levels of Notch1 and inflammatory cytokines[147].

\section{Alternative Medicine}

At a dose of 2.5 gm twice daily, Oral curcumin lowered pain associated with delayed onset muscle soreness (DOMS), caused by muscle damage or high-intensity eccentric exercise, by down-regulating blood cytokines activity up-regulating blood interleukin-6 (IL-6) concentration. It led to muscle regeneration and improvement in damage markers [127]. Systemic treatment with curcumin reduced the expressions of VEGF, TGF- $\beta 1$, and IGF1 among growth factors in prostate tissue, which were examined by immunohistochemistry and western-blot. It was orally administered at the concentration of $50 \mathrm{mg} / \mathrm{kg}$ for 4 weeks. It is efficient against testosterone-induced benign prostatic hyperplasia (BPH), multifactorial disease, and prostrate volume in the rat model [128]. Meriva, a novel lecithin-based deliver a form of curcumin, can be regarded as adjuvant therapy in people affected by psoriasis Vulgaris. Due to its interaction with the main pathogenic pathways of this disease, i.e., T cell-mediated inflammation by the obstruction of nuclear factor kappa $\mathrm{B}(\mathrm{NF}-\kappa \mathrm{B})$, keratinocyte proliferation which in return inhibited phosphorylase kinase $(\mathrm{PhK})$ [148]. Some patients were assigned to 12 weeks of treatment with oral curcumin and steroids, whereas others were treated with the steroid alone. It was observed that there was a significantly higher reduction in the serum levels of IL-22 in the patients treated with both oral curcumin and steroid [149]. Tetrahydrocurcuminoids(THCs), the natural antioxidants, have displayed higher bioavailability and physiological stability and a wide spectrum of therapeutic activities. Patients are suffering from canker sore and gingivitis (a gum disease) treated with 2 chewable tablets per day (each tablet containing 100mg of THCs) for 3 weeks. The results demonstrated that THCs reduced canker sore-induced features, including great reduction in redding at the site, trouble in swallowing, and chewing. It was also demonstrated that THCs could be regarded as a safe and effective ingredient, useful for treating patients with gingivitis. THCs downregulated the gingival appearance, bleeding, inflammation in the gingival patients without any side effects [150]. There is an increasing interest in using bisdemethoxycurcumin (BDMC) to prevent disorders associated with aging and cellular senescence. It was marked that BDMC could obviate t-BHP induced cellular senescence and elevate the level of both Sirt1 protein and mRNA, which in turn increased the AMPK phosphorylation after 48hrs of treatment. These effects are considered as the important link between cell metabolism and stress response [151]. 


\section{Others}

Inflammation and oxidative stress are the two causes of metabolic syndrome[152]. The bioavailability, solubility, and physiological response of curcumin can be enhanced by curcumin nanoparticle formulations in poly (lactic-co-glycolic acid) (PLGA). It was concluded that low-dose curcumin nanoparticles $(5 \mathrm{mg} / \mathrm{kg} /$ day for 8 weeks) produced the same physiological responses as high-dose curcumin suspension $(100 \mathrm{mg} / \mathrm{kg} / \mathrm{day}$ for 8 weeks), showing that a lower dose of curcumin nanoparticles have a protective role in metabolic syndrome. Curcumin PLGA nanoparticles reduced blood pressure, enhanced left ventricular function and liver fat deposition but caused basic improvement in high-carbohydrate and highfat diet-fed rats due to lower doses. These physiological responses led to higher plasma concentrations, which attenuated metabolic syndrome [126]. Several studies proved that curcumin administration could be considered a promising agent in the treatment of cardiovascular diseases. The anti-inflammatory properties, inhibition of oxidative stress, and activation of associated cardioprotective pathways contribute to the cardioprotective activities of curcumin. Cardiovascular diseases result in cardiac fibrosis, and it is known that curcumin exhibits anti-fibrotic impacts. Curcumin plays a vital role in suppressing myocardial infarction and normalizing blood pressure. The cell hypertrophy and nucleus enlargement in the left ventricular of the heart can be controlled by chitosan-encapsulated curcumin [153]. It was reported that the curcumin-loaded nanoparticles could improve the functions of the heart, including cardiac systolic and diastolic functions [154]. Furthermore, curcumin acts as a barrier for the RhoA/Rho-kinase pathway, leading to the deactivation of NF- $\mathrm{BB}$ and mitogen-activated protein kinase pathways that promote myocardial hypertrophy and hypertension, and heart failure. In addition, curcumin accelerated the activation of the mammalian target of rapamycin, which further inhibits autophagy and security against cardiac hypertrophy [155]. Natural products and many formulations derived from flora and fauna have been observed to have excellent biological and pharmaceutical functions owing to the presence of several active compounds with enhanced unique functional abilities[156-169] (Table 2).

Table 2. Curcuminoids based formulations and their biological applications.

\begin{tabular}{|c|c|c|c|c|}
\hline Formulations & Study Parameters & Activity & Outcomes of Curcumin Treatment & Ref. \\
\hline $\begin{array}{l}\text { Ferrous and ferric salt } \\
\text { solution }+ \text { Tween- } 60+ \\
\text { sodium hydroxide }+ \\
\text { acetone + CUR }\end{array}$ & $\begin{array}{l}\text { Physicochemical } \\
\text { characteristics }\end{array}$ & $\begin{array}{l}\text { Anti-inflammatory } \\
\text { and Antioxidant }\end{array}$ & $\begin{array}{l}\text { Higher 1,1- -diphenyl-2-picrylhydrazyl radical } \\
\text { scavenging and superoxide dismutase activities. } \\
\text { Suppress synthesis of lipopolysaccharide- } \\
\text { induced nitric oxide and release of interleukin- } \\
1 \beta \text { and tumor necrosis factor- } \alpha \text {. }\end{array}$ & [31] \\
\hline $\begin{array}{l}\text { Chemically modified } \\
\text { curcumin analogs }\end{array}$ & Cytotoxicity & Anti-Microbial & $\begin{array}{l}\text { 1,7-bis(4-hydroxy-3- methoxyphenyl) hept-4- } \\
\text { en-3-one exhibited most antileishmanial activity }\end{array}$ & [156] \\
\hline $\begin{array}{l}\text { Structurally modified to } 55 \\
\text { CUR, DMC, and BDMC } \\
\text { analogs }\end{array}$ & Cytotoxicity & Anti-Microbial & $\begin{array}{l}\text { The presence of a p-alkoxyl (-OR) group on the } \\
\text { Aromatic ring in close proximity to the nitrogen } \\
\text { function of the isoxazole ring and a free p- } \\
\text { hydroxyl (-OH) group on another ring increases } \\
\text { the biological activity }\end{array}$ & [157] \\
\hline $\begin{array}{l}\text { C5-curcumin-2- } \\
\text { hexadecynoic acid }\end{array}$ & Cytotoxicity & Anti-Microbial & $\begin{array}{l}\text { The conjugate was active against eight } \\
\text { Methicillin-resistant } S \text {. aureus strains at MICs } \\
\text { due to the presence of 2-hexadecynoic acid and } \\
\text { also increased } 4-8 \text { times its antibacterial activity }\end{array}$ & [158] \\
\hline $\begin{array}{l}\text { Curcumin-chitosan blend } \\
\text { film }\end{array}$ & $\begin{array}{l}\text { Physicochemical } \\
\text { characteristics }\end{array}$ & Anti-Microbial & $\begin{array}{l}\text { Elevates antibacterial activity against } \\
\text { Staphylococcus aureus and Rhizoctoniasolani }\end{array}$ & [159] \\
\hline Tf-CUR-SLNPs & $\begin{array}{l}\text { Cytotoxicity and cell } \\
\text { viability }\end{array}$ & Anti-cancer & $\begin{array}{l}\text { Cell uptake increased compared to CUR and } \\
\text { CUR loaded SLNPs against MCF-7 breast } \\
\text { cancer cells }\end{array}$ & [160] \\
\hline
\end{tabular}




\begin{tabular}{|c|c|c|c|c|}
\hline Formulations & Study Parameters & Activity & Outcomes of Curcumin Treatment & Ref. \\
\hline $\begin{array}{l}\text { CUR-PTX (paclitaxel) } \\
\text { administered in oil-in- } \\
\text { water nano-emulsion }\end{array}$ & $\begin{array}{l}\text { Nano-emulsion } \\
\text { formulations delivery } \\
\text { systems }\end{array}$ & Anti-cancer & $\begin{array}{l}\text { Enhanced anti-tumor activity against SKOV3 } \\
\text { tumor-bearing nu/nu female mice }\end{array}$ & [161] \\
\hline $\begin{array}{l}\text { Carboxymethylcellulose- } \\
\text { THC conjugates }\end{array}$ & $\begin{array}{l}\text { Cytotoxicity and cell } \\
\text { viability }\end{array}$ & Anti-cancer & $\begin{array}{l}\text { Selective cytotoxicity against Human colon } \\
\text { adenocarcinoma cell lines (HT-29) }\end{array}$ & {$[162]$} \\
\hline $\begin{array}{l}\text { Cyclic CUR analogs }+ \\
\text { aromatic aldehyde }\end{array}$ & In vitro bioassays & Anti-cancer & $\begin{array}{l}\text { Cytostatic activity against murine and human } \\
\text { cancer cell lines }\end{array}$ & [163] \\
\hline $\begin{array}{l}\text { Soy phosphatidylcholine + } \\
\text { sodium hyaluronate + } \\
\text { CUR }+ \text { ultrasonic } \\
\text { disintegrator }\end{array}$ & $\begin{array}{l}\text { Skin permeation and } \\
\text { cell viability }\end{array}$ & $\begin{array}{l}\text { Anti-inflammatory } \\
\text { and Antioxidant }\end{array}$ & $\begin{array}{l}\text { Improvement in antioxidant and free radical } \\
\text { scavenging activity which decreased MPO } \\
\text { activity. }\end{array}$ & [164] \\
\hline CUR bisacetamides & $\begin{array}{l}\text { In vitro release and } \\
\text { Cytotoxicity }\end{array}$ & $\begin{array}{l}\text { Anti-inflammatory } \\
\text { and Antioxidant }\end{array}$ & $\begin{array}{l}\text { Significant improvement in Bovine serum } \\
\text { albumin assay and A549 cancer cell line }\end{array}$ & {$[165]$} \\
\hline $\begin{array}{l}\text { 3(5)-trifluoromethyl-5(3)- } \\
\text { substituted-styryl-1H- } \\
\text { pyrazoles derived from } \\
\text { curcuminoids }\end{array}$ & In vitro determination & Anti-inflammatory & NOS inhibitory activity was higher by $50 \%$ & [166] \\
\hline $\begin{array}{l}\text { Ferrocenyl-substituted } \\
\text { CUR derivatives }\end{array}$ & Cytotoxicity & Antioxidant & $\begin{array}{l}\text { Protective effects against DPPH, ABTSp and } \\
\text { galvinoxyl radical. }\end{array}$ & {$[167]$} \\
\hline $\begin{array}{lr}\text { CUR } & \text { loaded } \\
\text { nanostructured } & \text { lipid } \\
\text { carriers } & \\
\end{array}$ & $\begin{array}{l}\text { Encapsulation } \\
\text { efficiency }\end{array}$ & $\begin{array}{l}\text { Neuroprotective } \\
\text { aspects }\end{array}$ & $\begin{array}{l}\text { Decreases histone acetylation in the CNS and } \\
\text { induces a marked hypoacetylation of histone } 4 \\
\text { (H4) at lysine } 12 \text { (K12) in the spinal cord. }\end{array}$ & [168] \\
\hline CUR derivatives & Pharmaceutical agents & $\begin{array}{l}\text { Neuroprotective } \\
\text { aspects }\end{array}$ & $\begin{array}{l}\text { CUR stimulated GLP-1 secretion in } \\
\text { GLUTagcellswhich leads to an increase in } \mathrm{Ca}^{2+}- \\
\text { CaMKII pathway. }\end{array}$ & [169] \\
\hline
\end{tabular}

\section{Conclusion and Future Dimension}

Curcuminoids are an active ingredient of the Curcuma longa rhizome that has been utilized since ancient times as spices and food additive colorants. In the past few years, this species has been explored extensively for its biological and pharmaceutical activities such as anti-inflammatory, antidiabetic, anticancer, antioxidant, hepatoprotective, neuroprotective, cardioprotective, etc. The documental records also found the use of turmeric in alternative systems of medicines like Indian Ayurveda, Sidha, Unani, and the Chinese medicine system. Recent progress of curcumin and its derivatives as promising bioactive and pharmaceutical agents with emphasis on future research dimensions required to propose curcuminoids as promising candidates for therapeutic and pharmacology-related sectors have been explored in this review. However, curcumin showed top-level pharmacological, biological, and therapeutic properties, yet there are still several issues to be concentrated on regarding mainly its bioavailability, potency, and specificity for the target tissue. Further researches are needed on the modern trends via futuristic medicinal chemistry approaches. These opportunities in the natural products might provide realistic future directions, particularly towards the nanoformulations based on curcuminoids, alone or in a combination of another suitable candidate performing biological and pharmaceutical functionalization.

\section{Funding}

This research received no external funding.

\section{Acknowledgments}

Prof. S. A. Ahmed, Vive-Chancellor, is highly acknowledged for his suggestive and positive moral support. 


\section{Conflicts of Interest}

The authors declare no conflict of interest and approve the final submission of the manuscript.

\section{References}

1. De, R.; Kundu, P.; Swarnakar, S.; Ramamurthy, T.; Chowdhury, A.; Nair, G.B.; Mukhopadhyay, A.K. Antimicrobial Activity of Curcumin against Helicobacter pylori Isolates from India and during Infections in Mice Antimicrobial Activity of Curcumin against Helicobacter pylori Isolates from India and during Infections in Mice. Antimicrobial Agents Chemother. 2009, 53, 1592-1597, https://doi.org/10.1128/AAC.01242-08.

2. Pawar, H. Phytochemical Evaluation and Curcumin Content Determination of Turmeric Rhizomes Collected From Bhandara District of Maharashtra (India). Med. Chem. (Los Angeles)2014, 4, 588-591, https://doi.org/10.4172/2161-0444.1000198.

3. Aggarwal, B.B. and Sung, B. Pharmacological basis for the role of curcumin in chronic diseases: an age-old spice with modern targets. Trends Pharmacol. Sci.2009, 30, 85-94, https://doi.org/10.1016/j.tips.2008.11.002.

4. Casas-Catalán, M.J.; Doménech-Carbó, M.T. Identification of natural dyes used in works of art by pyrolysisgas chromatography/mass spectrometry combined with in situ trimethylsilylation. Analytical and Bioanalytical Chemistry 2005, 382, 259-268,https://doi.org/10.1007/s00216-005-3064-0.

5. Srimal, R.C.; Dhawan, B.N. Pharmacology of diferuloyl methane (curcumin), a non-steroidal antiinflammatory agent*. Journal of Pharmacy and Pharmacology 1973, 25, 447452,https://doi.org/10.1111/j.2042-7158.1973.tb09131.x.

6. Indira Priyadarsini, K. Chemical and Structural Features Influencing the Biological Activity of Curcumin. Current Pharmaceutical Design 2013, 19, 2093-2100,https://doi.org/10.2174/138161213805289228.

7. López-Lázaro, M. Anticancer and carcinogenic properties of curcumin: Considerations for its clinical development as a cancer chemopreventive and chemotherapeutic agent. Molecular Nutrition \& Food Research 2008, 52, S103-S127,https://doi.org/10.1002/mnfr.200700238.

8. Wang, Y.-J.; Pan, M.-H.; Cheng, A.-L.; Lin, L.-I.; Ho, Y.-S.; Hsieh, C.-Y.; Lin, J.-K. Stability of curcumin in buffer solutions and characterization of its degradation products. Journal of Pharmaceutical and Biomedical Analysis 1997, 15, 1867-1876,https://doi.org/10.1016/S0731-7085(96)02024-9.

9. Sharma, R.A.; Gescher, A.J.; Steward, W.P. Curcumin: The story so far. European Journal of Cancer 2005, 41, 1955-1968,https://doi.org/10.1016/j.ejca.2005.05.009.

10. Anand, P.; Kunnumakkara, A.B.; Newman, R.A.; Aggarwal, B.B. Bioavailability of Curcumin: Problems and Promises. Molecular Pharmaceutics 2007, 4, 807-818,https://doi.org/10.1021/mp700113r.

11. Ak, T.; Gülçin, İ. Antioxidant and radical scavenging properties of curcumin. Chemico-biological interactions 2008, 174, 27-37,https://doi.org/10.1016/j.cbi.2008.05.003.

12. Kant, V.; Gopal, A.; Pathak, N.N.; Kumar, P.; Tandan, S.K.; Kumar, D. Antioxidant and anti-inflammatory potential of curcumin accelerated the cutaneous wound healing in streptozotocin-induced diabetic rats. International Immunopharmacology 2014, 20, 322-330,https://doi.org/10.1016/j.intimp.2014.03.009.

13. Mun, S.-H.; Joung, D.-K.; Kim, Y.-S.; Kang, O.-H.; Kim, S.-B.; Seo, Y.-S.; Kim, Y.-C.; Lee, D.-S.; Shin, D.-W.; Kweon, K.-T.; Kwon, D.-Y. Synergistic antibacterial effect of curcumin against methicillin-resistant Staphylococcus aureus. Phytomedicine 2013, 20, 714-718,https://doi.org/10.1016/j.phymed.2013.02.006.

14. Singh, R.K.; Rai, D.; Yadav, D.; Bhargava, A.; Balzarini, J.; De Clercq, E. Synthesis, antibacterial and antiviral properties of curcumin bioconjugates bearing dipeptide, fatty acids and folic acid. European Journal of Medicinal Chemistry 2010, 45, 1078-1086,https://doi.org/10.1016/j.ejmech.2009.12.002.

15. Liang, G.; Yang, S.; Zhou, H.; Shao, L.; Huang, K.; Xiao, J.; Huang, Z.; Li, X. Synthesis, crystal structure and anti-inflammatory properties of curcumin analogues. European Journal of Medicinal Chemistry 2009, 44, 915-919,https://doi.org/10.1016/j.ejmech.2008.01.031.

16. Wright, E.L.; Frye, B.J.; Gorti, B.; Timmermann, N.B.; Funk, L.J. Bioactivity of Turmeric-derived Curcuminoids and Related Metabolites in Breast Cancer. Current Pharmaceutical Design 2013, 19, 62186225,https://doi.org/10.2174/1381612811319340013.

17. Sharma, O.P. Antioxidant activity of curcumin and related compounds. Biochem Pharmacol 1976, 25, 18111812, https://doi.org/10.1016/0006-2952(76)90421-4.

18. Aggarwal, B.B.; Sundaram, C.; Malani, N.; Ichikawa, H. Curcumin: the Indian solid gold. Advances in experimental medicine and biology 2007, 595, 1-75, https://doi.org/10.1007/978-0-387-46401-5_1.

19. Kloesch, B.; Becker, T.; Dietersdorfer, E.; Kiener, H.; Steiner, G. Anti-inflammatory and apoptotic effects of the polyphenol curcumin on human fibroblast-like synoviocytes. International Immunopharmacology 2013, 15, 400-405, https://doi.org/10.1016/j.intimp.2013.01.003.

20. Kant, V.; Gopal, A.; Kumar, D.; Pathak, N.N.; Ram, M.; Jangir, B.L.; Tandan, S.K.; Kumar, D. Curcumininduced angiogenesis hastens wound healing in diabetic rats. Journal of Surgical Research 2015, 193, 978988, https://doi.org/10.1016/j.jss.2014.10.019. 
21. Gupta, S.C.; Patchva, S.; Aggarwal, B.B. Therapeutic Roles of Curcumin: Lessons Learned from Clinical Trials. The AAPS Journal 2013, 15, 195-218, https://doi.org/10.1208/s12248-012-9432-8.

22. Panahi, Y.; Hosseini, M.S.; Khalili, N.; Naimi, E.; Simental-Mendía, L.E.; Majeed, M.; Sahebkar, A. Effects of curcumin on serum cytokine concentrations in subjects with metabolic syndrome: A post-hoc analysis of a randomized controlled trial. Biomedicine \& Pharmacotherapy 2016, 82, 578-582, https://doi.org/10.1016/j.biopha.2016.05.037.

23. Kuptniratsaikul, V.; Dajpratham, P.; Taechaarpornkul, W.; Buntragulpoontawee, M.; Lukkanapichonchut, P.; Chootip, C.; Saengsuwan, J.; Tantayakom, K.; Laongpech, S. Efficacy and safety of Curcuma domestica extracts compared with ibuprofen in patients with knee osteoarthritis: A multicenter study. Clin. Interv. Aging2014, 9, 451-458, https://doi.org/10.2147/cia.s58535.

24. Mazzolani, F.; Togni, S. Oral administration of a curcumin-phospholipid delivery system for the treatment of central serous chorioretinopathy: A 12-month follow-up study. Clin. Ophthalmol.2013, 7, 939945,https://doi.org/10.2147/OPTH.S45820.

25. Trujillo, J.; Chirino, Y.I.; Molina-Jijón, E.; Andérica-Romero, A.C.; Tapia, E.; Pedraza-Chaverrí, J. Renoprotective effect of the antioxidant curcumin: Recent findings. Redox Biology 2013, 1, 448-456, https://doi.org/10.1016/j.redox.2013.09.003.

26. Aggarwal, B.B.; Harikumar, K.B. Potential therapeutic effects of curcumin, the anti-inflammatory agent, against neurodegenerative, cardiovascular, pulmonary, metabolic, autoimmune and neoplastic diseases. The International Journal of Biochemistry \& Cell Biology 2009, 41, 4059,https://doi.org/10.1016/j.biocel.2008.06.010.

27. Basnet, P.; Skalko-Basnet, N. Curcumin: An Anti-Inflammatory Molecule from a Curry Spice on the Path to Cancer Treatment. Molecules 2011, 16, 4567-4598, https://doi.org/10.3390/molecules16064567.

28. Lao, C.D.; Ruffin, M.T.; Normolle, D.; Heath, D.D.; Murray, S.I.; Bailey, J.M.; Boggs, M.E.; Crowell, J.; Rock, C.L.; Brenner, D.E. Dose escalation of a curcuminoid formulation. BMC Complementary and Alternative Medicine 2006, 6, 1-4,https://doi.org/10.1186/1472-6882-6-10.

29. Wilken, R.; Veena, M.S.; Wang, M.B.; Srivatsan, E.S. Curcumin: A review of anti-cancer properties and therapeutic activity in head and neck squamous cell carcinoma. Molecular Cancer 2011, 10, 119,https://doi.org/10.1186/1476-4598-10-12.

30. Souza, C.R.A.; Osme, S.F.; Glória, M.B.A. Stability Of Curcuminoib Pigments In Model Systems. Journal of Food Processing and Preservation 1997, 21, 353-363, https://doi.org/10.1111/j.17454549.1997.tb00789.x.

31. Psimadas, D.; Georgoulias, P.; Valotassiou, V.; Loudos, G. Molecular Nanomedicine Towards Cancer: 111In-Labeled Nanoparticles. Journal of Pharmaceutical Sciences 2012, 101, 22712280,https://doi.org/10.1002/jps.23146.

32. Tønnesen, H.H.; Másson, M.; Loftsson, T. Studies of curcumin and curcuminoids. XXVII. Cyclodextrin complexation: solubility, chemical and photochemical stability. International Journal of Pharmaceutics 2002, 244, 127-135,https://doi.org/10.1016/S0378-5173(02)00323-X.

33. Wang, S.; Yang, W.; Shen, H. Genetic diversity in Apium graveolens and related species revealed by SRAP and SSR markers. Scientia Horticulturae 2011, 129, 1-8, https://doi.org/10.1016/j.scienta.2011.03.020.

34. Han, H.-K. The effects of black pepper on the intestinal absorption and hepatic metabolism of drugs. Expert Opinion on Drug Metabolism \& Toxicology 2011, $\quad 7, \quad$ 721-729, https://doi.org/10.1517/17425255.2011.570332.

35. Shoba, G.; Joy, D.; Joseph, T.; Majeed, M.; Rajendran, R.; Srinivas, P.S.S.R. Influence of piperine on the pharmacokinetics of curcumin in animals and human volunteers. Planta Med.1998, 64, 353356,https://doi.org/10.1055/s-2006-957450.

36. Yang, M.-Y.; Chang, K.-C.; Chen, L.-Y.; Hu, A. Low-dose blue light irradiation enhances the antimicrobial activities of curcumin against Propionibacterium acnes. Journal of Photochemistry and Photobiology B: Biology 2018, 189, 21-28,https://doi.org/10.1016/j.jphotobiol.2018.09.021.

37. Shakeri, A.; Panahi, Y.; Johnston, T.P.; Sahebkar, A. Biological properties of metal complexes of curcumin. BioFactors 2019, 45, 304-317,https://doi.org/10.1002/biof.1504.

38. Tyagi, P.; Singh, M.; Kumari, H.; Kumari, A.; Mukhopadhyay, K. Bactericidal Activity of Curcumin I Is Associated with Damaging of Bacterial Membrane. PLOS ONE 2015, 10,https://doi.org/10.1371/journal.pone.0121313.

39. Imlay, J.A. Pathways of oxidative damage. Annual Rev. Microbiol. 2003, 57, 395418,https://doi.org/10.1146/annurev.micro.57.030502.090938.

40. Itzia Azucena, R.C.; José Roberto, C.L.; Martin, Z.R.; Rafael, C.Z.; Leonardo, H.H.; Gabriela, T.P. and Araceli, C.R. Drug susceptibility testing and synergistic antibacterial activity of curcumin with antibiotics against enterotoxigenic Escherichia coli. Antibiotics, 2019, 8, https://doi.org/10.3390/antibiotics8020043.

41. Shabangu, S.M.; Babu, B.; Soy, R.C.; Oyim, J.; Amuhaya, E.; Nyokong, T. Susceptibility of Staphylococcus aureus to porphyrin-silver nanoparticle mediated photodynamic antimicrobial chemotherapy. Journal of Luminescence 2020, 222, 117-158, https://doi.org/10.1016/j.jlumin.2020.117158.

42. Karthikeyan, A.; Senthil, N.; Min, T. Nanocurcumin: A Promising Candidate for Therapeutic Applications. Frontiers in Pharmacology 2020, 11,https://doi.org/10.3389/fphar.2020.00487. 
43. Mohammed, N.A.; Habil, N.Y. Evaluation of antimicrobial activity of curcumin against two oral bacteria. Autom. Control Intell. Syst.2015, 3, 18-21,https://doi.org/10.11648/j.acis.s.2015030201.14.

44. Sharma, G.; Raturi, K.; Dang, S.; Gupta, S.; Gabrani, R. Combinatorial antimicrobial effect of curcumin with selected phytochemicals on Staphylococcus epidermidis. Journal of Asian Natural Products Research 2014, 16, 535-541,https://doi.org/10.1080/10286020.2014.911289.

45. Liu, C.H.; Huang, H.Y. Antimicrobial activity of curcumin-loaded myristic acid microemulsions against Staphylococcus epidermidis. Chemical \& pharmaceutical bulletin 2012, 60, 1118-1124, https://doi.org/10.1248/cpb.c12-00220.

46. Reddy, N.; Han, S.; Zhao, Y.; Yang, Y. Antimicrobial activity of cotton fabrics treated with curcumin. Journal of Applied Polymer Science 2013, 127, 2698-2702, https://doi.org/10.1002/app.37613.

47. Barua, S.; Chattopadhyay, P.; Phukan, M.M.; Konwar, B.K.; Islam, J.; Karak, N. Biocompatible hyperbranched epoxy/silver-reduced graphene oxide-curcumin nanocomposite as an advanced antimicrobial material. RSC Advances 2014, 4, 47797-47805,https://doi.org/10.1039/C4RA07802K.

48. Krausz, A.E.; Adler, B.L.; Cabral, V.; Navati, M.; Doerner, J.; Charafeddine, R.A.; Chandra, D.; Liang, H.; Gunther, L.; Clendaniel, A.; Harper, S.; Friedman, J.M.; Nosanchuk, J.D.; Friedman, A.J. Curcuminencapsulated nanoparticles as innovative antimicrobial and wound healing agent. Nanomedicine 2015, 11, 195-206, https://doi.org/10.1016/j.nano.2014.09.004.

49. Infante, K.; Chowdhury, R.; Nimmanapalli, R.; Reddy, G. Antimicrobial activity of curcumin against foodborne pathogens. Vedic Res. Int. Biological Med. Chem.2014, 2, 1219,https://doi.org/10.14259/bmc.v2i1.102.

50. Bray, F.; Ferlay, J.; Soerjomataram, I.; Siegel, R.L.; Torre, L.A.; Jemal, A. Global cancer statistics 2018: GLOBOCAN estimates of incidence and mortality worldwide for 36 cancers in 185 countries. CA Cancer J Clin 2018, 68, 394-424, https://doi.org/10.3322/caac.21492.

51. Goel, A.; Kunnumakkara, A.B.; Aggarwal, B.B. Curcumin as "Curecumin": From kitchen to clinic. Biochemical Pharmacology 2008, 75, 787-809,https://doi.org/10.1016/j.bcp.2007.08.016.

52. Balasubramanian, S.; Eckert, R.L. Curcumin Suppresses AP1 Transcription Factor-dependent Differentiation and Activates Apoptosis in Human Epidermal Keratinocytes *. Journal of Biological Chemistry 2007, 282, 6707-6715,https://doi.org/10.1074/jbc.M606003200.

53. Cheng, M.A.; Chou, F.-J.; Wang, K.; Yang, R.; Ding, J.; Zhang, Q.; Li, G.; Yeh, S.; Xu, D.; Chang, C. Androgen receptor (AR) degradation enhancer ASC-J9® in an FDA-approved formulated solution suppresses castration resistant prostate cancer cell growth. Cancer Letters 2018, 417, 182191,https://doi.org/10.1016/j.canlet.2017.11.038.

54. Verderio, P.; Pandolfi, L.; Mazzucchelli, S.; Marinozzi, M.R.; Vanna, R.; Gramatica, F.; Corsi, F.; Colombo, M.; Morasso, C.; Prosperi, D. Antiproliferative Effect of ASC-J9 Delivered by PLGA Nanoparticles against Estrogen-Dependent Breast Cancer Cells. Molecular Pharmaceutics 2014, 11, 2864-2875, https://doi.org/10.1021/mp500222k.

55. Qiu, P.; Zhang, S.; Zhou, Y.; Zhu, M.; Kang, Y.; Chen, D.; Wang, J.; Zhou, P.; Li, W.; Xu, Q.; Jin, R.; Wu, J.; Liang, G. Synthesis and evaluation of asymmetric curcuminoid analogs as potential anticancer agents that downregulate NF- $\mathrm{kB}$ activation and enhance the sensitivity of gastric cancer cell lines to irinotecan chemotherapy. European Journal of Medicinal Chemistry 2017, 139, 917925,https://doi.org/10.1016/j.ejmech.2017.08.022.

56. Theppawong, A.; Van de Walle, T.; Grootaert, C.; Bultinck, M.; Desmet, T.; Van Camp, J.; D'Hooghe, M. Synthesis of Novel Aza-aromatic Curcuminoids with Improved Biological Activities towards Various Cancer Cell Lines. ChemistryOpen 2018, 7, 381-392,https://doi.org/10.1002/open.201800029.

57. Yodkeeree, S.; Chaiwangyen, W.; Garbisa, S.; Limtrakul, P. Curcumin, demethoxycurcumin and bisdemethoxycurcumin differentially inhibit cancer cell invasion through the down-regulation of MMPs and uPA. The Journal of Nutritional Biochemistry 2009, 20, 87-95, https://doi.org/10.1016/j.jnutbio.2007.12.003.

58. Yodkeeree, S.; Chaiwangyen, W.; Garbisa, S.; Limtrakul, P. Curcumin, demethoxycurcumin and bisdemethoxycurcumin differentially inhibit cancer cell invasion through the down-regulation of MMPs and $\begin{array}{llllll}\text { uPA. The Journal of Nutritional Biochemistry 2009, } & \text { 20, }\end{array}$ https://doi.org/10.1016/j.phymed.2015.08.006.

59. Ye, M.-X.; Zhao, Y.-L.; Li, Y.; Miao, Q.; Li, Z.-K.; Ren, X.-L.; Song, L.-Q.; Yin, H.; Zhang, J. Curcumin reverses cis-platin resistance and promotes human lung adenocarcinoma A549/DDP cell apoptosis through HIF-1 $\alpha$ and caspase-3 mechanisms. Phytomedicine 2012, 19, 779-787, https://doi.org/10.1016/j.phymed.2012.03.005.

60. Du, Q.; Hu, B.; An, H.-M.; Shen, K.-P.; Xu, L.; Deng, S.; Wei, M.-M. Synergistic anticancer effects of curcumin and resveratrol in Hepa1-6 hepatocellular carcinoma cells. Oncol Rep 2013, 29, 18511858,https://doi.org/10.3892/or.2013.2310.

61. Yan, G.; Graham, K.; Lanza-Jacoby, S. Curcumin enhances the anticancer effects of trichostatin a in breast cancer cells. Molecular Carcinogenesis 2013, 52, 404-411,https://doi.org/10.1002/mc.21875.

62. Einbond, L.S.; Wu, H.-a.; Kashiwazaki, R.; He, K.; Roller, M.; Su, T.; Wang, X.; Goldsberry, S. Carnosic acid inhibits the growth of ER-negative human breast cancer cells and synergizes with curcumin. Fitoterapia 2012, 83, 1160-1168,https://doi.org/10.1016/j.fitote.2012.07.006. 
63. Lin, H.-Y.; Lin, J.-N.; Ma, J.-W.; Yang, N.-S.; Ho, C.-T.; Kuo, S.-C.; Way, T.-D. Demethoxycurcumin induces autophagic and apoptotic responses on breast cancer cells in photodynamic therapy. Journal of Functional Foods 2015, 12, 439-449,https://doi.org/10.1016/j.jff.2014.12.014.

64. Mudduluru, G.; George-William, J.N.; Muppala, S.; Asangani, I.A.; Kumarswamy, R.; Nelson, L.D. and Allgayer, H. Curcumin regulates miR-21 expression and inhibits invasion and metastasis in colorectal cancer. Biosci. Rep.2011, 31, 185-197,https://doi.org/10.1042/BSR20100065.

65. Chuah, L.H.; Roberts, C.J.; Billa, N.; Abdullah, S.; Rosli, R. Cellular uptake and anticancer effects of mucoadhesive curcumin-containing chitosan nanoparticles. Colloids and Surfaces B: Biointerfaces 2014, 116, 228-236,https://doi.org/10.1016/j.colsurfb.2014.01.007.

66. Yallapu, M.M.; Khan, S.; Maher, D.M.; Ebeling, M.C.; Sundram, V.; Chauhan, N.; Ganju, A.; Balakrishna, S.; Gupta, B.K.; Zafar, N.; Jaggi, M.; Chauhan, S.C. Anti-cancer activity of curcumin loaded nanoparticles in prostate cancer. Biomaterials 2014, 35, 8635-8648,https://doi.org/10.1016/j.biomaterials.2014.06.040.

67. Weller, J.; Budson, A. Current understanding of Alzheimer's disease diagnosis and treatment. F1000Research2018, 7, 1-9,https://doi.org/10.12688/f1000research.14506.1.

68. Ferrari, E.; Benassi, R.; Sacchi, S.; Pignedoli, F.; Asti, M.; Saladini, M. Curcumin derivatives as metalchelating agents with potential multifunctional activity for pharmaceutical applications. J. Inorg. Biochem.2014, 139, 38-48, https://doi.org/10.1016/j.jinorgbio.2014.06.002.

69. Sun, Q.; Liu, F.; Sang, J.; Lin, M.; Ma, J.; Xiao, X.; Yan, S.; Naman, C.B.; Wang, N.; He, S.; Yan, X.; Cui, W.; Liang, H. 9-Methylfascaplysin Is a More Potent A $\beta$ Aggregation Inhibitor than the Marine-Derived Alkaloid, Fascaplysin, and Produces Nanomolar Neuroprotective Effects in SH-SY5Y Cells. Marine Drugs 2019, 17,https://doi.org/10.3390/md17020121.

70. Ooko, E.; Alsalim, T.; Saeed, B.; Saeed, M.E.M.; Kadioglu, O.; Abbo, H.S.; Titinchi, S.J.J.; Efferth, T. Modulation of P-glycoprotein activity by novel synthetic curcumin derivatives in sensitive and multidrugresistant T-cell acute lymphoblastic leukemia cell lines. Toxicology and Applied Pharmacology 2016, 305, 216-233,https://doi.org/10.1016/j.taap.2016.06.002.

71. Sanei, M.; Saberi-Demneh, A. Effect of curcumin on memory impairment: A systematic review. Phytomedicine 2019, 52, 98-106, https://doi.org/10.1016/j.phymed.2018.06.016.

72. Banerjee, R. Spectroscopy Effect of Curcumin on the metal ion induced fibrillization of Amyloid- $b$ peptide. Spectrochim. Acta Part A Mol. Biomol. Spectrosc.2014, 117, 798800,https://doi.org/10.1016/j.saa.2013.09.064.

73. Chittigori, J.; Kumar, A.; Li, L.; Thota, S.; Kokil, A.; Samuelson, L.A.; Sandman, D.J.; Kumar, J. Synthesis of a self organizable curcumin derivative and investigation of its interaction with metals in $100 \%$ aqueous media. Tetrahedron 2014, 70, 991-995,https://doi.org/10.1016/j.tet.2013.11.071.

74. Zhang, X.; Tian, Y.; Li, Z.; Tian, X.; Sun, H.; Liu, H.; Moore, A.; Ran, C. Design and Synthesis of Curcumin Analogues for in Vivo Fluorescence Imaging and Inhibiting Copper-Induced Cross-Linking of Amyloid Beta Species in Alzheimer's Disease. Journal of the American Chemical Society 2013, 135, 16397-16409, https://doi.org/10.1021/ja405239v.

75. Chen, S.-Y.; Chen, Y.; Li, Y.-P.; Chen, S.-H.; Tan, J.-H.; Ou, T.-M.; Gu, L.-Q.; Huang, Z.-S. Design, synthesis, and biological evaluation of curcumin analogues as multifunctional agents for the treatment of Alzheimer's disease. Bioorganic \& Medicinal Chemistry 2011, 19, 5596-5604, https://doi.org/10.1016/j.bmc.2011.07.033.

76. Bicer, N.; Yildiz, E.; Yegani, A.A.; Aksu, F. Synthesis of curcumin complexes with iron(iii) and manganese(ii), and effects of curcumin-iron(iii) on Alzheimer's disease. New Journal of Chemistry 2018, 42, 8098-8104,https://doi.org/10.1039/c7nj04223j.

77. SoukhakLari, R.; Moezi, L.; Pirsalami, F.; Ashjazadeh, N.; Moosavi, M. Curcumin ameliorates scopolamineinduced mice memory retrieval deficit and restores hippocampal p-Akt and p-GSK-3 $\beta$. European Journal of Pharmacology 2018, 841, 28-32, https://doi.org/10.1016/j.ejphar.2018.10.012.

78. Patel, C.; Pande, S.; Acharya, S. Potentiation of anti-Alzheimer activity of curcumin by probiotic Lactobacillus rhamnosus UBLR-58 against scopolamine-induced memory impairment in mice. NaunynSchmiedeberg's Archives of Pharmacology 2020, 393, 1955-1962, https://doi.org/10.1007/s00210-02001904-3.

79. Lu, W.-T.; Sun, S.-Q.; Li, Y.; Xu, S.-Y.; Gan, S.-W.; Xu, J.; Qiu, G.-P.; Zhuo, F.; Huang, S.-Q.; Jiang, X.L.; Huang, J. Curcumin Ameliorates Memory Deficits by Enhancing Lactate Content and MCT2 Expression in APP/PS1 Transgenic Mouse Model of Alzheimer's Disease. The Anatomical Record 2019, 302, 332338,https://doi.org/10.1002/ar.23969.

80. Ray, B.; Bisht, S.; Maitra, A.; Maitra, A.; Lahiri, D.K. Neuroprotective and neurorescue effects of a novel polymeric nanoparticle formulation of curcumin $\left(\mathrm{NanoCurc}^{\mathrm{TM}}\right)$ in the neuronal cell culture and animal model: Implications for Alzheimer's disease. J. Alzheimer's Dis.2011, 23, 61-77, https://doi.org/10.3233/JAD-2010101374.

81. Fang, L.; Gou, S.; Liu, X.; Cao, F.; Cheng, L. Design, synthesis and anti-Alzheimer properties of dimethylaminomethyl-substituted curcumin derivatives. Bioorganic \& Medicinal Chemistry Letters 2014, 24, 40-43,https://doi.org/10.1016/j.bmcl.2013.12.011. 
82. Llano, S.; Gómez, S.; Londoño, J.; Restrepo, A. Antioxidant activity of curcuminoids. Physical Chemistry Chemical Physics 2019, 21, 3752-3760,https://doi.org/10.1039/c8cp06708b.

83. Sökmen, M.; Akram Khan, M. The antioxidant activity of some curcuminoids and chalcones. Inflammopharmacology 2016, 24, 81-86, https://doi.org/10.1007/s10787-016-0264-5.

84. Squillaro, T.; Cimini, A.; Peluso, G.; Giordano, A.; Melone, M.A.B. Nano-delivery systems for encapsulation of dietary polyphenols: An experimental approach for neurodegenerative diseases and brain tumors. Biochemical Pharmacology 2018, 154, 303-317,https://doi.org/10.1016/j.bcp.2018.05.016.

85. Kocher, A.; Schiborr, C.; Behnam, D.; Frank, J. The oral bioavailability of curcuminoids in healthy humans is markedly enhanced by micellar solubilisation but not further improved by simultaneous ingestion of sesamin, ferulic acid, naringenin and xanthohumol. Journal of Functional Foods 2015, 14, 183-191, https://doi.org/10.1016/j.jff.2015.01.045.

86. Mošovská, S.; Petáková, P.; Kaliňák, M.; Mikulajová, A. Antioxidant properties of curcuminoids isolated from L. Acta Chimica Slovaca 2016, 9, 130-135,https://doi.org/10.1515/acs-2016-0022.

87. Zhang, J.; Han, H.; Shen, M.; Zhang, L.; Wang, T. Comparative Studies on the Antioxidant Profiles of Curcumin and Bisdemethoxycurcumin in Erythrocytes and Broiler Chickens. Animals 2019, 9,https://doi.org/10.3390/ani9110953.

88. Kou, M.-C.; Chiou, S.-Y.; Weng, C.-Y.; Wang, L.; Ho, C.-T.; Wu, M.-J. Curcuminoids distinctly exhibit antioxidant activities and regulate expression of scavenger receptors and heme oxygenase-1. Molecular Nutrition \& Food Research 2013, 57, 1598-1610,https://doi.org/10.1002/mnfr.201200227.

89. Panahi, Y.; Khalili, N.; Sahebi, E.; Namazi, S.; Karimian, M.S.; Majeed, M.; Sahebkar, A. Antioxidant effects of curcuminoids in patients with type 2 diabetes mellitus: a randomized controlled trial. Inflammopharmacology 2017, 25, 25-31,https://doi.org/10.1007/s10787-016-0301-4.

90. Kalaycıoğlu, Z.; Gazioğlu, I.; Erim, F.B. Comparison of antioxidant, anticholinesterase, and antidiabetic activities of three curcuminoids isolated from Curcuma longa L. Natural Product Research 2017, 31, 29142917, https://doi.org/10.1080/14786419.2017.1299727.

91. Li, X.; Xie, Y.; Xie, H.; Yang, J.; Chen, D. $\pi-\pi$ Conjugation Enhances Oligostilbene's Antioxidant Capacity: Evidence from $\alpha$-Viniferin and Caraphenol A. Molecules 2018, 23,https://doi.org/10.3390/molecules23030694.

92. Zhao, X.-C.; Zhang, L.; Yu, H.-X.; Sun, Z.; Lin, X.-F.; Tan, C.; Lu, R.-R. Curcumin protects mouse neuroblastoma Neuro-2A cells against hydrogen-peroxide-induced oxidative stress. Food Chemistry 2011, 129, 387-394,https://doi.org/10.1016/j.foodchem.2011.04.089.

93. Öz, A.; Çelik, Ö. Curcumin inhibits oxidative stress-induced TRPM2 channel activation, calcium ion entry and apoptosis values in SH-SY5Y neuroblastoma cells: Involvement of transfection procedure. Molecular Membrane Biology 2016, 33, 76-88,https://doi.org/10.1080/09687688.2017.1318224.

94. Ibrahim, J.; Kabiru, A.Y.; Abdulrasheed-Adeleke, T.; Lawal, B.; Adewuyi, A.H. Antioxidant and hepatoprotective potentials of curcuminoid isolates from turmeric (Curcuma longa) rhizome on CCl4-induced hepatic damage in Wistar rats. Journal of Taibah University for Science 2020, 14, 908-915, https://doi.org/10.1080/16583655.2020.1790928.

95. Panahi, Y.; Alishiri, G.H.; Parvin, S.; Sahebkar, A. Mitigation of Systemic Oxidative Stress by Curcuminoids in Osteoarthritis: Results of a Randomized Controlled Trial. Journal of Dietary Supplements 2016, 13, 209220, https://doi.org/10.3109/19390211.2015.1008611.

96. Panahi, Y.; Hosseini, M.S.; Khalili, N.; Naimi, E.; Majeed, M.; Sahebkar, A. Antioxidant and antiinflammatory effects of curcuminoid-piperine combination in subjects with metabolic syndrome: A randomized controlled trial and an updated meta-analysis. Clinical Nutrition 2015, 34, 11011108,https://doi.org/10.1016/j.clnu.2014.12.019.

97. Handler, N.; Jaeger, W.; Puschacher, H.; Leisser, K.; Erker, T. Synthesis of Novel Curcumin Analogues and Their Evaluation as Selective Cyclooxygenase-1 (COX-1) Inhibitors. Chemical and Pharmaceutical Bulletin 2007, 55, 64-71,https://doi.org/10.1248/cpb.55.64.

98. Zhou, H.; Beevers, S.C.; Huang, S. The Targets of Curcumin. Current Drug Targets 2011, 12, 332-347, https://doi.org/10.2174/138945011794815356.

99. Banuppriya, G.; Sribalan, R.; Padmini, V.; Shanmugaiah, V. Biological evaluation and molecular docking studies of new curcuminoid derivatives: Synthesis and characterization. Bioorganic \& Medicinal Chemistry Letters 2016, 26, 1655-1659,https://doi.org/10.1016/j.bmcl.2016.02.066.

100.Panahi, Y.; Sahebkar, A.; Parvin, S.; Saadat, A. A randomized controlled trial on the anti-inflammatory effects of curcumin in patients with chronic sulphur mustard-induced cutaneous complications. Annals of Clinical Biochemistry 2012, 49, 580-588,https://doi.org/10.1258/acb.2012.012040.

101.Zhang, Y.; Liang, D.; Dong, L.; Ge, X.; Xu, F.; Chen, W.; Dai, Y.; Li, H.; Zou, P.; Yang, S.; Liang, G. Antiinflammatory effects of novel curcumin analogs in experimental acute lung injury. Respiratory Research 2015, 16, 1-13,https://doi.org/10.1186/s12931-015-0199-1.

102.Cao, J.; Ye, B.; Lin, L.; Tian, L.; Yang, H.; Wang, C.; Huang, W.; Huang, Z. Curcumin Alleviates oxLDL Induced MMP-9 and EMMPRIN Expression through the Inhibition of NF- $\kappa \mathrm{B}$ and MAPK Pathways in Macrophages. Frontiers in Pharmacology 2017, 8, 1-9,https://doi.org/10.3389/fphar.2017.00062. 
103.Liu, T.; Li, C.; Sun, H.; Luo, T.; Tan, Y.; Tian, D.; Guo, Z. Curcumin inhibits monocyte chemoattractant protein-1 expression and enhances cholesterol efflux by suppressing the c-Jun N-terminal kinase pathway in macrophage. Inflammation Research 2014, 63, 841-850,https://doi.org/10.1007/s00011-014-0758-9.

104.Panahi, Y.; Khalili, N.; Sahebi, E.; Namazi, S.; Reiner, Ž.; Majeed, M.; Sahebkar, A. Curcuminoids modify lipid profile in type 2 diabetes mellitus: A randomized controlled trial. Complementary Therapies in Medicine 2017, 33, 1-5,https://doi.org/10.1016/j.ctim.2017.05.006.

105.Bo, L.-J.; Miao, Z.; Wang, Z.-F.; Zhang, K.-Z.; Gao, Z. A study on effect of curcumin on anticerebral aneurysm in the male albino rats. Brain and Behavior 2017, 7, 1-10,https://doi.org/10.1002/brb3.729.

106.Karaman, M.; Firinci, F.; Cilaker, S.; Uysal, P.; Tugyan, K.; Yilmaz, O.; Uzuner, N.; Karaman, O. Antiinflammatory effects of curcumin in a murine model of chronic asthma. Allergologia et Immunopathologia 2012, 40, 210-214,https://doi.org/10.1016/j.aller.2011.04.006.

107.Kim, D.-C.; Lee, W.; Bae, J.-S. Vascular anti-inflammatory effects of curcumin on HMGB1-mediated responses in vitro. Inflammation Research 2011, 60, 1161-1168,https://doi.org/10.1007/s00011-011-0381-y.

108.Cooney, J.M.; Barnett, M.P.G.; Dommels, Y.E.M.; Brewster, D.; Butts, C.A.; McNabb, W.C.; Laing, W.A.; Roy, N.C. A combined omics approach to evaluate the effects of dietary curcumin on colon inflammation in the Mdr1a-/- mouse model of inflammatory bowel disease. The Journal of Nutritional Biochemistry 2016, 27, 181-192,https://doi.org/10.1016/j.jnutbio.2015.08.030.

109. Maiti, P.; Paladugu, L.; Dunbar, G.L. Solid lipid curcumin particles provide greater anti-amyloid, antiinflammatory and neuroprotective effects than curcumin in the 5xFAD mouse model of Alzheimer's disease. BMC Neuroscience 2018, 19, 1-18,https://doi.org/10.1186/s12868-018-0406-3.

110.Zhang, Y.; Zhao, C.; He, W.; Wang, Z.; Fang, Q.; Xiao, B.; Liu, Z.; Liang, G.; Yang, S. Discovery and evaluation of asymmetrical monocarbonyl analogs of curcumin as anti-inflammatory agents. Drug Design, Development Ther.2014, 8, 373-382,http://dx.doi.org/10.2147/DDDT.S58168.

111.Hussain, Z.; Thu, H.E.; Amjad, M.W.; Hussain, F.; Ahmed, T.A.; Khan, S. Exploring recent developments to improve antioxidant, anti-inflammatory and antimicrobial efficacy of curcumin: A review of new trends and future perspectives. Materials Science and Engineering: $C$ 2017, 77, 13161326,https://doi.org/10.1016/j.msec.2017.03.226.

112.Vos, T.; Allen, C.; Arora, M.; Barber, R.M.; Bhutta, Z.A.; Brown, A.; Carter, A.; Casey, D.C.; Charlson, F.J.; Chen, A.Z.; Coggeshall, M. Global, regional, and national incidence, prevalence, and years lived with disability for 310 diseases and injuries, 1990-2015: a systematic analysis for the Global Burden of Disease Study 2015. TheLancet2016, 388, 1545-1602,https://doi.org/10.1016/S0140-6736(16)31678-6.

113. Ahmad, B.; Lapidus, L.J. Curcumin prevents aggregation in $\alpha$-synuclein by increasing reconfiguration rate. J. Biol. Chem.2012, 287, 9193-9199, https://doi.org/10.1074/jbc.M111.325548.

114.Du, X.-X.; Xu, H.-M.; Jiang, H.; Song, N.; Wang, J.; Xie, J.-X. Curcumin protects nigral dopaminergic neurons by iron-chelation in the 6-hydroxydopamine rat model of Parkinson's disease. Neuroscience Bulletin 2012, 28, 253-258,https://doi.org/10.1007/s12264-012-1238-2.

115. Yang, J.; Song, S.; Li, J.; Liang, T. Neuroprotective effect of curcumin on hippocampal injury in 6-OHDAinduced Parkinson's disease rat. Pathology - Research and Practice 2014, 210, 357-362, https://doi.org/10.1016/j.prp.2014.02.005.

116. Yadav, R.S.; Chandravanshi, L.P.; Shukla, R.K.; Sankhwar, M.L.; Ansari, R.W.; Shukla, P.K.; Pant, A.B.; Khanna, V.K. Neuroprotective efficacy of curcumin in arsenic induced cholinergic dysfunctions in rats. NeuroToxicology 2011, 32, 760-768,https://doi.org/10.1016/j.neuro.2011.07.004.

117.Gazal, M.; Valente, M.R.; Acosta, B.A.; Kaufmann, F.N.; Braganhol, E.; Lencina, C.L.; Stefanello, F.M.; Ghisleni, G.; Kaster, M.P. Neuroprotective and antioxidant effects of curcumin in a ketamine-induced model of mania in rats. European Journal of Pharmacology 2014, 724, 132-139, https://doi.org/10.1016/j.ejphar.2013.12.028.

118.Dong, W.; Yang, B.; Wang, L.; Li, B.; Guo, X.; Zhang, M.; Jiang, Z.; Fu, J.; Pi, J.; Guan, D.; Zhao, R. Curcumin plays neuroprotective roles against traumatic brain injury partly via Nrf2 signaling. Toxicology and Applied Pharmacology 2018, 346, 28-36,https://doi.org/10.1016/j.taap.2018.03.020.

119.Goldsmith, M.; Abramovitz, L.; Peer, D. Precision Nanomedicine in Neurodegenerative Diseases. ACS Nano 2014, 8, 1958-1965,https://doi.org/10.1021/nn501292z.

120.Patel, T.; Zhou, J.; Piepmeier, J.M.; Saltzman, W.M. Polymeric nanoparticles for drug delivery to the central nervous system. Advanced Drug Delivery Reviews 2012, 64, 701705,https://doi.org/10.1016/j.addr.2011.12.006.

121.Davis, B.M.; Pahlitzsch, M.; Guo, L.; Balendra, S.; Shah, P.; Ravindran, N.; Malaguarnera, G.; Sisa, C.; Shamsher, E.; Hamze, H.; Noor, A.; Sornsute, A.; Somavarapu, S.; Cordeiro, M.F. Topical Curcumin Nanocarriers are Neuroprotective in Eye Disease. Scientific Reports 2018, 8,113,https://doi.org/10.1038/s41598-018-29393-8.

122. Cianciulli, A.; Calvello, R.; Porro, C.; Trotta, T.; Salvatore, R.; Panaro, M.A. PI3k/Akt signalling pathway plays a crucial role in the anti-inflammatory effects of curcumin in LPS-activated microglia. International Immunopharmacology 2016, 36, 282-290,https://doi.org/10.1016/j.intimp.2016.05.007. 
123. Ahmed, T.; Gilani, A.-H. Inhibitory effect of curcuminoids on acetylcholinesterase activity and attenuation of scopolamine-induced amnesia may explain medicinal use of turmeric in Alzheimer's disease. Pharmacology Biochemistry and Behavior 2009, 91, 554-559,https://doi.org/10.1016/j.pbb.2008.09.010.

124.Ahmed, T.; Enam, S.A.; Gilani, A.H. Curcuminoids enhance memory in an amyloid-infused rat model of $\begin{array}{lllll}\text { Alzheimer's } & \text { disease. } & \text { Neuroscience } & \text { 2010, } & \text { 169, }\end{array}$ https://doi.org/10.1016/j.neuroscience.2010.05.078.

125.Villaflores, O.B.; Chen, Y.-J.; Chen, C.-P.; Yeh, J.-M.; Wu, T.-Y. Effects of curcumin and demethoxycurcumin on amyloid- $\beta$ precursor and tau proteins through the internal ribosome entry sites: A potential therapeutic for Alzheimer's disease. Taiwanese Journal of Obstetrics and Gynecology 2012, 51, 554-564,https://doi.org/10.1016/j.tjog.2012.09.010.

126.du Preez, R.; Pahl, J.; Arora, M.; Ravi Kumar, M.N.V.; Brown, L.; Panchal, S.K. Low-Dose Curcumin Nanoparticles Normalise Blood Pressure in Male Wistar Rats with Diet-Induced Metabolic Syndrome. Nutrients 2019, 11,https://doi.org/10.3390/nu11071542.

127.Nicol, L.M.; Rowlands, D.S.; Fazakerly, R.; Kellett, J. Curcumin supplementation likely attenuates delayed onset muscle soreness (DOMS). European Journal of Applied Physiology 2015, 115, 17691777,https://doi.org/10.1007/s00421-015-3152-6.

128.Kim, S.K.; Seok, H.; Park, H.J.; Jeon, H.S.; Kang, S.W.; Lee, B.-C.; Yi, J.; Song, S.Y.; Lee, S.H.; Kim, Y.O.; Chung, J.-H. Inhibitory effect of curcumin on testosterone induced benign prostatic hyperplasia rat model. BMC Complementary and Alternative Medicine 2015, 15, 1-7,https://doi.org/10.1186/s12906-015-0825-y.

129.Wang, C.; Horby, P.W.; Hayden, F.G.; Gao, G.F. A novel coronavirus outbreak of global health concern. The Lancet 2020, 395, 470-473,https://doi.org/10.1016/S0140-6736(20)30185-9.

130. Kocaadam, B.; Şanlier, N. Curcumin, an active component of turmeric (Curcuma longa), and its effects on health. Critical Reviews in Food Science and Nutrition 2017, 57, 28892895,https://doi.org/10.1080/10408398.2015.1077195.

131.Zahedipour, F.; Hosseini, S.A.; Sathyapalan, T.; Majeed, M.; Jamialahmadi, T.; Al-Rasadi, K.; Banach, M.; Sahebkar, A. Potential effects of curcumin in the treatment of COVID-19 infection. Phytotherapy Research 2020, 34, 2911-2920, https://doi.org/10.1002/ptr.6738.

132.Narayan, V.; Ravindra, K.C.; Chiaro, C.; Cary, D.; Aggarwal, B.B.; Henderson, A.J.; Prabhu, K.S. Celastrol Inhibits Tat-Mediated Human Immunodeficiency Virus (HIV) Transcription and Replication. Journal of Molecular Biology 2011, 410, 972-983,https://doi.org/10.1016/j.jmb.2011.04.013.

133. Mounce, B.C.; Cesaro, T.; Carrau, L.; Vallet, T.; Vignuzzi, M. Curcumin inhibits Zika and chikungunya virus infection by inhibiting cell binding. Antiviral Research 2017, 142, 148-157, https://doi.org/10.1016/j.antiviral.2017.03.014.

134.Chen, T.-Y.; Chen, D.-Y.; Wen, H.-W.; Ou, J.-L.; Chiou, S.-S.; Chen, J.-M.; Wong, M.-L.; Hsu, W.-L. Inhibition of Enveloped Viruses Infectivity by Curcumin. PLOS ONE 2013, 8, 111,https://doi.org/10.1371/journal.pone.0062482.

135.Ibrahim, M.A.A.; Abdelrahman, A.H.M.; Hussien, T.A.; Badr, E.A.A.; Mohamed, T.A.; El-Seedi, H.R.; Pare, P.W.; Efferth, T.; Hegazy, M.-E.F. In silico drug discovery of major metabolites from spices as SARS-CoV2 main protease inhibitors. Computers in Biology and Medicine 2020, 126,https://doi.org/10.1016/j.compbiomed.2020.104046.

136.Sanidad, K.Z.; Sukamtoh, E.; Xiao, H.; McClements, D.J.; Zhang, G. Curcumin: Recent Advances in the Development of Strategies to Improve Oral Bioavailability. Annual Review of Food Science and Technology 2019, 10, 597-617,https://doi.org/10.1146/annurev-food-032818-121738.

137. Yallapu, M.M.; Jaggi, M.; Chauhan, S.C. Curcumin nanoformulations: a future nanomedicine for cancer. Drug Discovery Today 2012, 17, 71-80, https://doi.org/10.1016/j.drudis.2011.09.009.

138. Saber-Moghaddam, N.; Salari, S.; Hejazi, S.; Amini, M.; Taherzadeh, Z.; Eslami, S.; Rezayat, S.M.; Jaafari, M.R.; Elyasi, S. Oral nano-curcumin formulation efficacy in management of mild to moderate hospitalized coronavirus disease-19 patients: An open label nonrandomized clinical trial. Phytotherapy Research 2021, 35, 2616-2623,https://doi.org/10.1002/ptr.7004.

139. Valizadeh, H.; Abdolmohammadi-vahid, S.; Danshina, S.; Ziya Gencer, M.; Ammari, A.; Sadeghi, A.; Roshangar, L.; Aslani, S.; Esmaeilzadeh, A.; Ghaebi, M.; Valizadeh, S.; Ahmadi, M. Nano-curcumin therapy, a promising method in modulating inflammatory cytokines in COVID-19 patients. International Immunopharmacology 2020, 89,https://doi.org/10.1016/j.intimp.2020.107088.

140.Mauricio, M.D.; Guerra-Ojeda, S.; Marchio, P.; Valles, S.L.; Aldasoro, M.; Escribano-Lopez, I.; Herance, J.R.; Rocha, M.; Vila, J.M.; Victor, V.M. Nanoparticles in Medicine: A Focus on Vascular Oxidative Stress. Oxidative Medicine and Cellular Longevity 2018, 2018,https://doi.org/10.1155/2018/6231482.

141.Salleh, A.; Naomi, R.; Utami, N.D.; Mohammad, A.W.; Mahmoudi, E.; Mustafa, N.; Fauzi, M.B. The Potential of Silver Nanoparticles for Antiviral and Antibacterial Applications: A Mechanism of Action. Nanomaterials 2020, 10, 1-20,https://doi.org/10.3390/nano10081566.

142.Ting, D.; Dong, N.; Fang, L.; Lu, J.; Bi, J.; Xiao, S.; Han, H. Multisite Inhibitors for Enteric Coronavirus: Antiviral Cationic Carbon Dots Based on Curcumin. ACS Applied Nano Materials 2018, 1, 5451-5459, https://doi.org/10.1021/acsanm.8b00779. 
143.Sacchi, M.C.; Tamiazzo, S.; Stobbione, P.; Agatea, L.; De Gaspari, P.; Stecca, A.; Lauritano, E.C.; Roveta, A.; Tozzoli, R.; Guaschino, R.; Bonometti, R. SARS-CoV-2 infection as a trigger of autoimmune response. Clinical and Translational Science 2021, 14, 898-907,https://doi.org/10.1111/cts.12953.

144.Roy, R.; Bhowmik, R.; Seth, S. Bhattacharyya, S.; Sengupta, S. Computational Repurposing Model of Curcumin as a Drug. Int. J. Pharm. Sci. Rev. Res.2021, 68,https://doi.org/10.47583/ijpsrr.2021.v68i01.026.

145. Singh, K. Potential role of Curcumin against viral infections with a view on structure and pathogenesis of COVID-19. AIJR Preprints2020, 213, 1-8, https://doi.org/10.21467/preprints.213.

146.Lupfer, C.; Kanneganti, T.-D. The expanding role of NLRs in antiviral immunity. Immunological Reviews 2013, 255, 13-24,https://doi.org/10.1111/imr.12089.

147.Jiang, L.; Fei, D.; Gong, R.; Yang, W.; Yu, W.; Pan, S.; Zhao, M.; Zhao, M. CORM-2 inhibits TXNIP/NLRP3 inflammasome pathway in LPS-induced acute lung injury. Inflammation Research 2016, 65, 905-915, https://doi.org/10.1007/s00011-016-0973-7.

148.Gupta, S.C.; Tyagi, A.K.; Deshmukh-Taskar, P.; Hinojosa, M.; Prasad, S.; Aggarwal, B.B. Downregulation of tumor necrosis factor and other proinflammatory biomarkers by polyphenols. Archives of Biochemistry and Biophysics 2014, 559, 91-99,https://doi.org/10.1016/j.abb.2014.06.006.

149. Antiga, E.; Bonciolini, V.; Volpi, W.; Del Bianco, E.; Caproni, M. Oral Curcumin (Meriva) Is Effective as an Adjuvant Treatment and Is Able to Reduce IL-22 Serum Levels in Patients with Psoriasis Vulgaris. BioMed Research International 2015, 2015,https://doi.org/10.1155/2015/283634.

150. Majeed, M.; Majeed, S.; Nagabhushanam, K. Efficacy and Safety of Tetrahydrocurcuminoids for the Treatment of Canker Sore and Gingivitis. Evidence-Based Complementary and Alternative Medicine 2020, 2020,https://doi.org/10.1155/2020/6611877.

151.Li, Y.B.; Zhong, Z.F.; Chen, M.W.; Bao, J.L.; Wu, G.S.; Zhang, Q.W.; Lee, S.M.Y.; Hoi, P.M.; Wang, Y.T. Bisdemethoxycurcumin Increases Sirt1 to Antagonize t -BHP-Induced Premature Senescence in WI38 Fibroblast Cells. Evidence-Based Complem. Alternat. Med.2013,2013,https://doi.org/10.1155/2013/851714.

152. O'Neill, S.; O'Driscoll, L. Metabolic syndrome: a closer look at the growing epidemic and its associated pathologies. Obesity Reviews 2015, 16, 1-12,https://doi.org/10.1111/obr.12229.

153.Sudirman, S.; Lai, C.-S.; Yan, Y.-L.; Yeh, H.-I.; Kong, Z.-L. Histological evidence of chitosan-encapsulated curcumin suppresses heart and kidney damages on streptozotocin-induced type-1 diabetes in mice model. Scientific Reports 2019, 9, 1-11,https://doi.org/10.1038/s41598-019-51821-6.

154.Liu, Y.; Liu, Q.; Liu, Y.; Ju, F.; Ma, Q.; He, Q. In vivo evaluation of enhanced drug carrier efficiency and cardiac anti-hypertrophy therapeutic potential of nano-curcumin encapsulated photo-plasmonic nanoparticles combined polymerized nano-vesicles: A novel strategy. Journal of Photochemistry and Photobiology B: Biology 2019, 199,https://doi.org/10.1016/j.jphotobiol.2019.111619.

155.Wang, N.-P.; Wang, Z.-F.; Tootle, S.; Philip, T.; Zhao, Z.-Q. Curcumin promotes cardiac repair and ameliorates cardiac dysfunction following myocardial infarction. British Journal of Pharmacology 2012, 167, 1550-1562,https://doi.org/10.1111/j.1476-5381.2012.02109.x.

156. Changtam, C.; de Koning, H.P.; Ibrahim, H.; Sajid, M.S.; Gould, M.K.; Suksamrarn, A. Curcuminoid analogs with potent activity against Trypanosoma and Leishmania species. European Journal of Medicinal Chemistry 2010, 45, 941-956,https://doi.org/10.1016/j.ejmech.2009.11.035.

157. Changtam, C.; Hongmanee, P.; Suksamrarn, A. Isoxazole analogs of curcuminoids with highly potent multidrug-resistant antimycobacterial activity. European Journal of Medicinal Chemistry 2010, 45, 44464457,https://doi.org/10.1016/j.ejmech.2010.07.003.

158.Sanabria-Ríos, D.J.; Rivera-Torres, Y.; Rosario, J.; Gutierrez, R.; Torres-García, Y.; Montano, N.; OrtízSoto, G.; Ríos-Olivares, E.; Rodríguez, J.W.; Carballeira, N.M. Chemical conjugation of 2-hexadecynoic acid to C5-curcumin enhances its antibacterial activity against multi-drug resistant bacteria. Bioorganic \& Medicinal Chemistry Letters 2015, 25, 5067-5071,https://doi.org/10.1016/j.bmcl.2015.10.022.

159.Liu, Y.; Cai, Y.; Jiang, X.; Wu, J.; Le, X. Molecular interactions, characterization and antimicrobial activity of curcumin-chitosan blend films. Food Hydrocolloids 2016, 52, 564-572, https://doi.org/10.1016/j.foodhyd.2015.08.005.

160.Mulik, R.S.; Mönkkönen, J.; Juvonen, R.O.; Mahadik, K.R.; Paradkar, A.R. Transferrin mediated solid lipid nanoparticles containing curcumin: Enhanced in vitro anticancer activity by induction of apoptosis. International Journal of Pharmaceutics 2010, 398, 190-203,https://doi.org/10.1016/j.ijpharm.2010.07.021.

161. Ganta, S.; Devalapally, H.; Amiji, M. Curcumin Enhances Oral Bioavailability and Anti-Tumor Therapeutic Efficacy of Paclitaxel upon Administration in Nanoemulsion Formulation. Journal of Pharmaceutical Sciences 2010, 99, 4630-4641,https://doi.org/10.1002/jps.22157.

162.Plyduang, T.; Lomlim, L.; Yuenyongsawad, S.; Wiwattanapatapee, R. Carboxymethylcellulosetetrahydrocurcumin conjugates for colon-specific delivery of a novel anti-cancer agent, 4-amino tetrahydrocurcumin. European Journal of Pharmaceutics and Biopharmaceutics 2014, 88, 351360,https://doi.org/10.1016/j.ejpb.2014.05.011.

163. Youssef, D.; Nichols, C.E.; Cameron, T.S.; Balzarini, J.; De Clercq, E.; Jha, A. Design, synthesis, and cytostatic activity of novel cyclic curcumin analogues. Bioorganic \& Medicinal Chemistry Letters 2007, 17, 5624-5629,https://doi.org/10.1016/j.bmcl.2007.07.079. 
164.Manca, M.L.; Castangia, I.; Zaru, M.; Nácher, A.; Valenti, D.; Fernàndez-Busquets, X.; Fadda, A.M.; Manconi, M. Development of curcumin loaded sodium hyaluronate immobilized vesicles (hyalurosomes) and their potential on skin inflammation and wound restoring. Biomaterials 2015, 71, 100109,https://doi.org/10.1016/j.biomaterials.2015.08.034.

165. Sribalan, R.; Kirubavathi, M.; Banuppriya, G.; Padmini, V. Synthesis and biological evaluation of new symmetric curcumin derivatives. Bioorganic \& Medicinal Chemistry Letters 2015, 25, 42824286,https://doi.org/10.1016/j.bmcl.2015.07.088.

166.Nieto, C.I.; Cabildo, M.P.; Cornago, M.P.; Sanz, D.; Claramunt, R.M.; Alkorta, I.; Elguero, J.; García, J.A.; López, A.; Acuña-Castroviejo, D. Synthesis, structure and biological activity of 3(5)-trifluoromethyl-1Hpyrazoles derived from hemicurcuminoids. Journal of Molecular Structure 2015, 1100, 518-529, https://doi.org/10.1016/j.molstruc.2015.07.055.

167.Li, P.-Z.; Liu, Z.-Q. Ferrocenyl-substituted curcumin: Can it influence antioxidant ability to protect DNA? European Journal of Medicinal Chemistry 2011, 46, 1821-1826, https://doi.org/10.1016/j.ejmech.2011.02.041.

168.Puglia, C.; Frasca, G.; Musumeci, T.; Rizza, L.; Puglisi, G.; Bonina, F.; Chiechio, S. Curcumin loaded NLC induces histone hypoacetylation in the CNS after intraperitoneal administration in mice. European Journal of Pharmaceutics and Biopharmaceutics 2012, 81, 288-293,https://doi.org/10.1016/j.ejpb.2012.03.015.

169.Takikawa, M.; Kurimoto, Y.; Tsuda, T. Curcumin stimulates glucagon-like peptide-1 secretion in GLUTag cells via $\mathrm{Ca} 2+/$ calmodulin-dependent kinase II activation. Biochemical and Biophysical Research Communications 2013, 435, 165-170,https://doi.org/10.1016/j.bbrc.2013.04.092. 